\title{
تنافسية المنشأة في ظل نظام التصنيع المرن دالة أستراتيجية التصنيع وهرونته- دراسة حالة
}

\author{
أ. م. مصطفى منير أسماعيل \\ جامعة بغذاد - كلية الادارة والاقتصاد مصن \\ قسم الأدارة الصناعية \\ قسم أدارة الاعمال
}

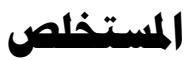

صمم البحث للراسة العلاقة بين أستراتيجية التصنيع ومرونته في ظل نظام التصنيع المرن وأنعكاس

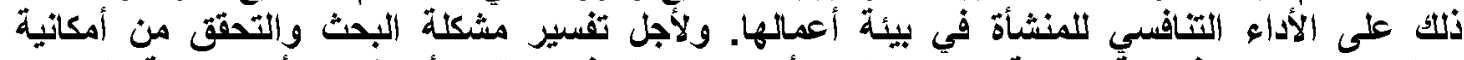
معالجتها، صيغت فرضية رئيسة نصت على "أن الاداء التنافسي للمنشأة تفسره أستراتيجية التصنيع

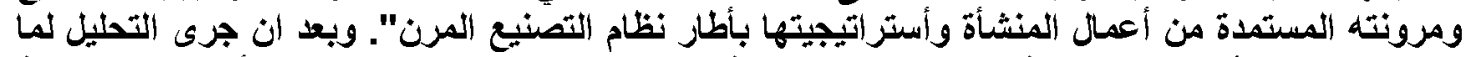

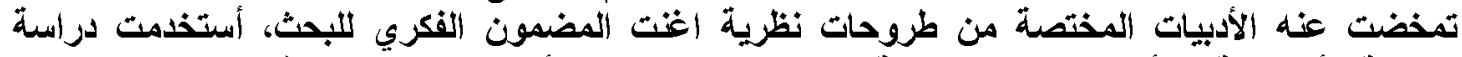

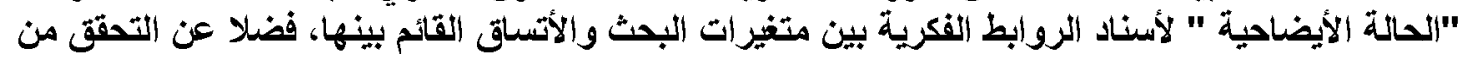

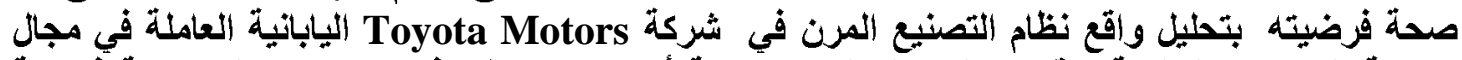

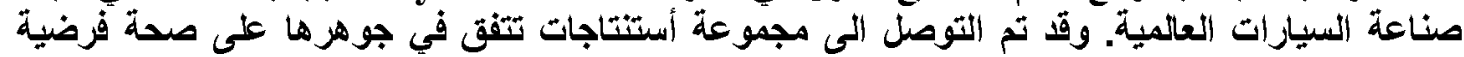
البحث ومنطقيتها.
\end{abstract}

\section{ABSTRACT}

The research has designed for studying the relationship between manufacturing strategy and its flexibility under the flexible manufacturing system with their reflection on the competitive environmental performance of the firm. To interpret and tackle the problem, a hypothesis has formulated stating that " the competitive performance of a firm is interpreted by the manufacturing strategy and flexibility which are derived from the firm and its business strategies under the flexible manufacturing system". Related literatures with their theoretical dissertations, which enhanced the thoughtful content, have analyzed. An illustrative case study on the flexible manufacturing system at Toyota Motors Corporation working at the global automobile industry is used for supporting the thoughtful linkages and consistency among the variables of the research. It has reached to many conclusions agreed in their essence upon validity of the hypothesis and its logic. 


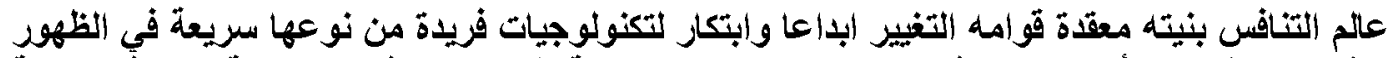

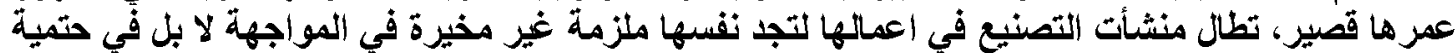

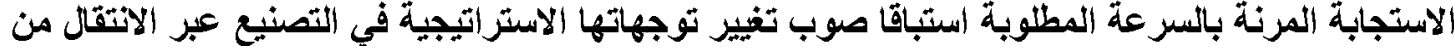

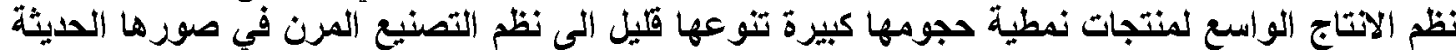

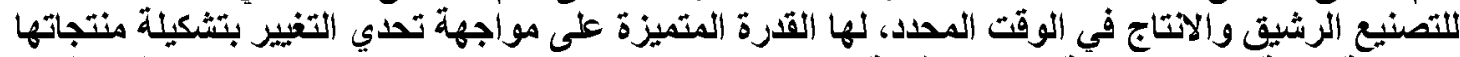

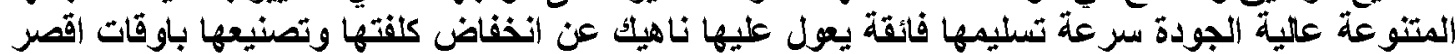

ومعدل استخدام اعلى لخطوط الخودة انتخاجها.

وعلى هذا النسث من التسبيب والتاويل اثر التحليل والتمحيص وانطلاقا من حقيقة ان الاداءو التخافسي

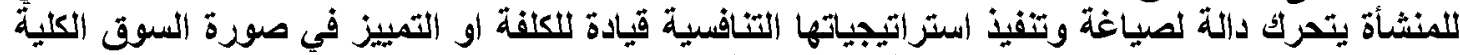

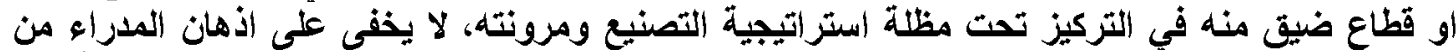

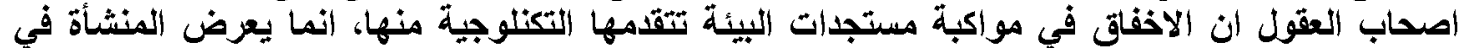

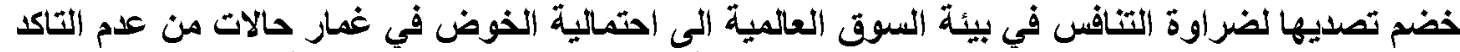

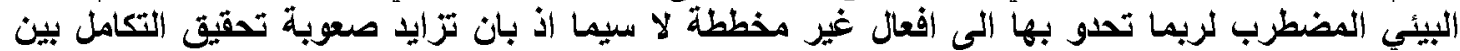

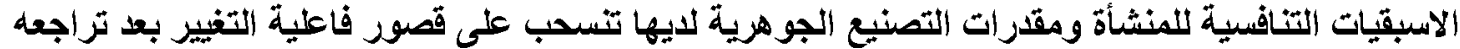

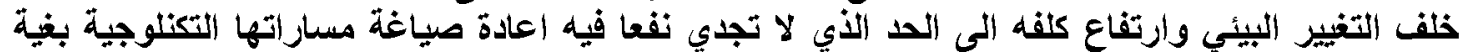

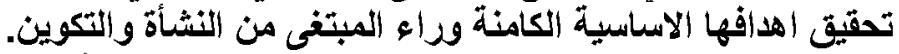

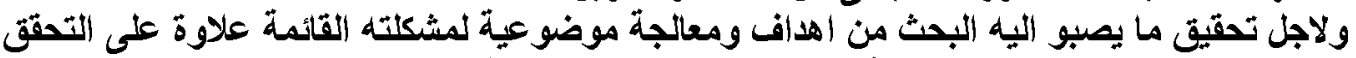

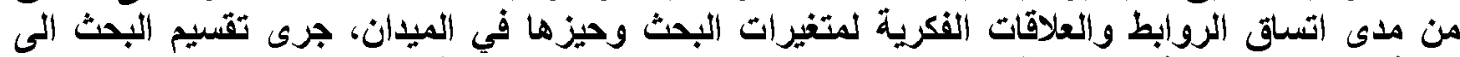

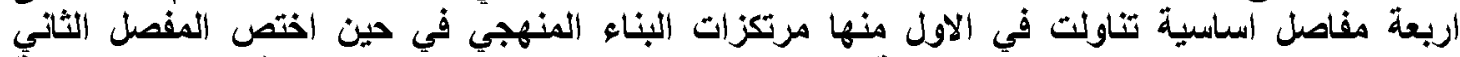

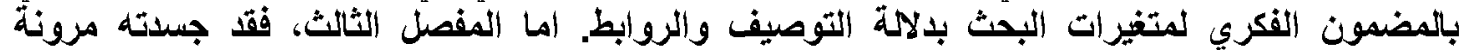

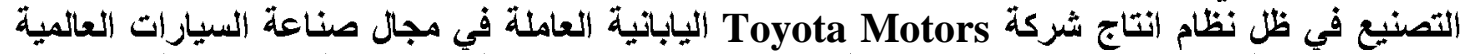

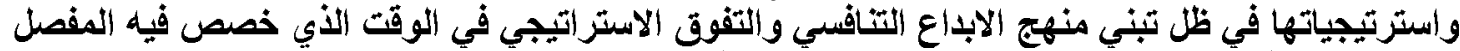

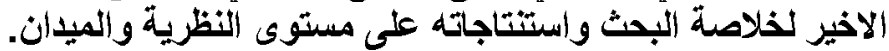

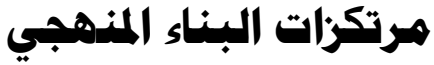

اولا / مشكلة البحث

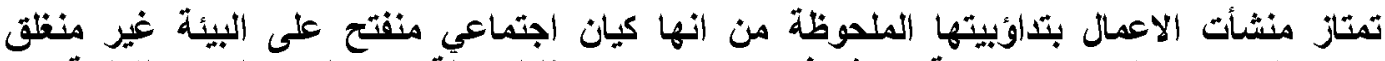

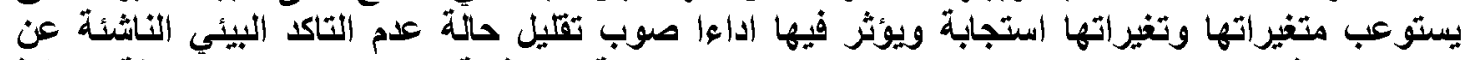

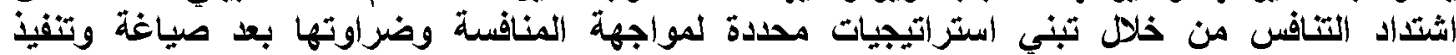
استراتيجيات تنافسية تقود ها استراتيجية التصنيع ومرونتهة. ولكن عملية تبني استراتيجية تصنية تصنيع تنافسية

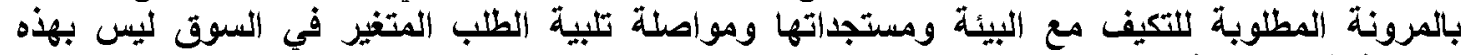

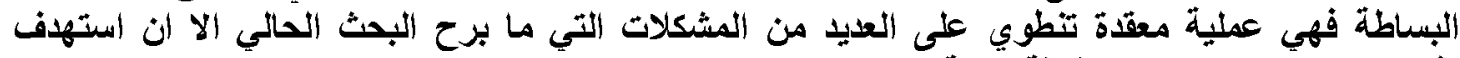
تلنيلها ومعالجتها بابعاد ها الثلاثة الآنية:

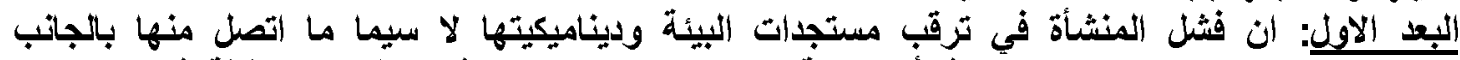

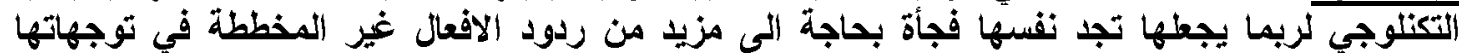

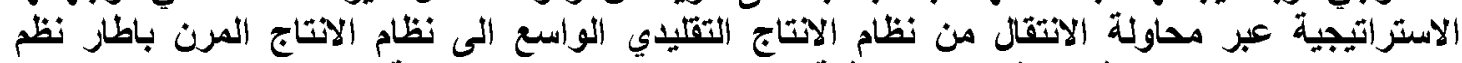

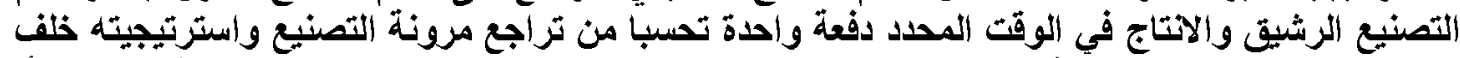

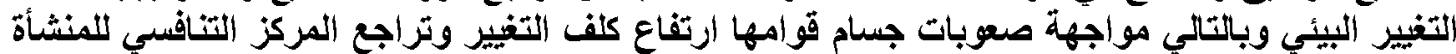
في بيئة اعمائها.

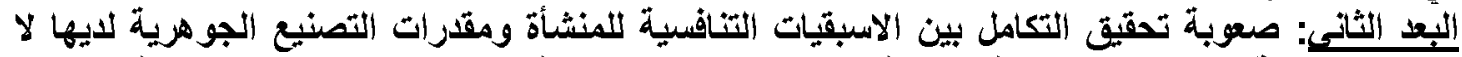

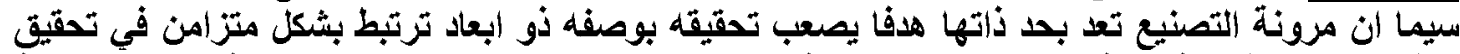

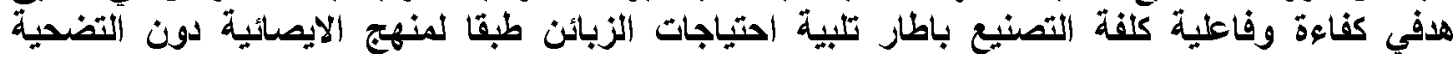


البعد الثالث: وتزداد المسألة تعقيا عندما يراد تحقيق نوع من التراصف الاستراتيجي بين مرونة التصنيع

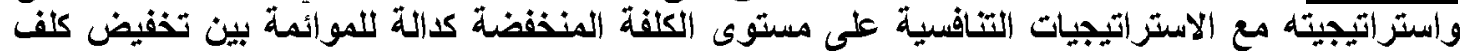

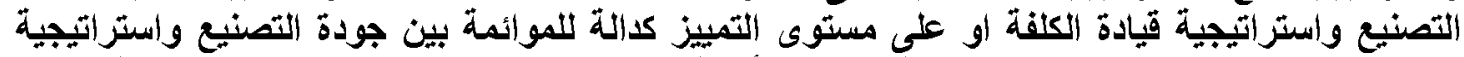

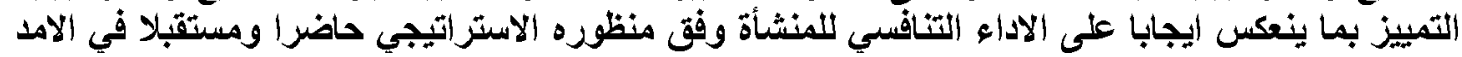

\section{ثانيا/ اهمية البية البمث واهدافهه}

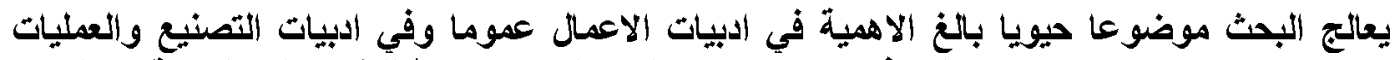

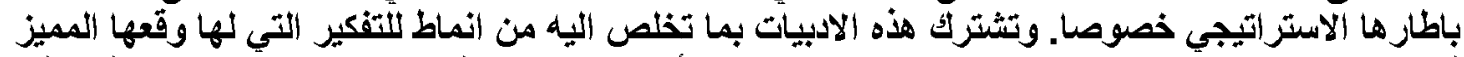

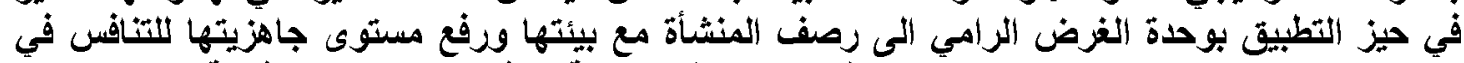

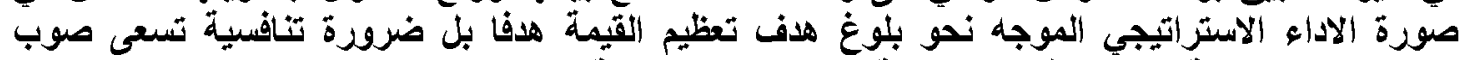

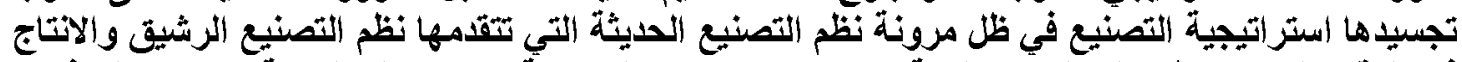

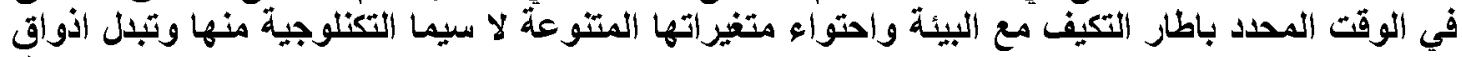

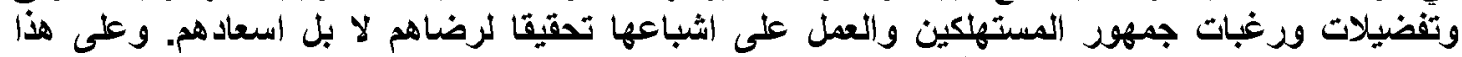

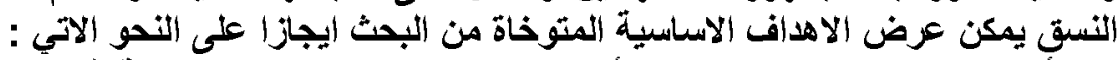

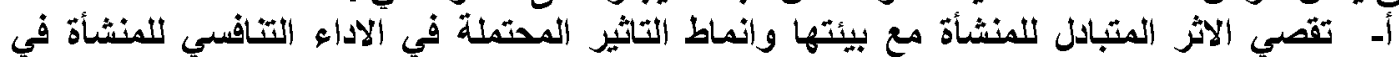

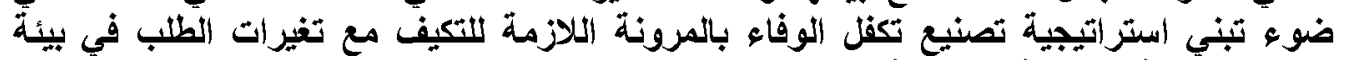

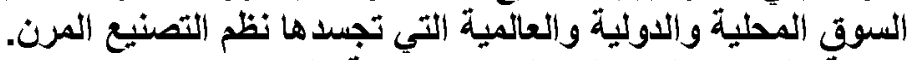

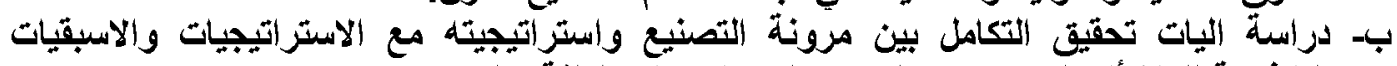

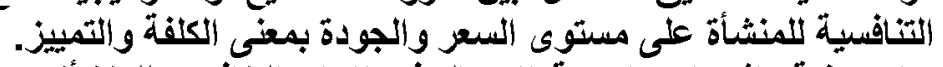

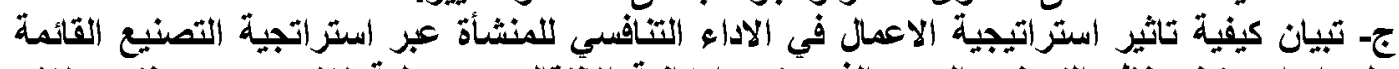

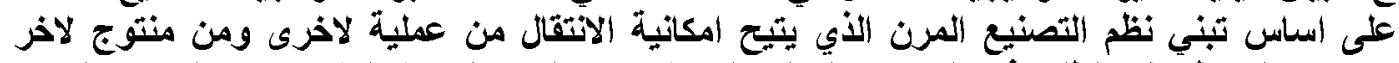

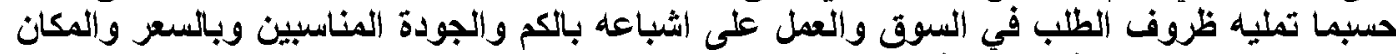

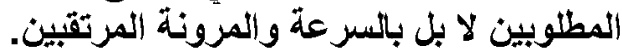

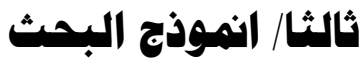

يوضح المخطط الاتي المبنية تفاصيله في الثكل رقم (1) المتغيرات الاساسية للبحث والعلاقيات القائمة

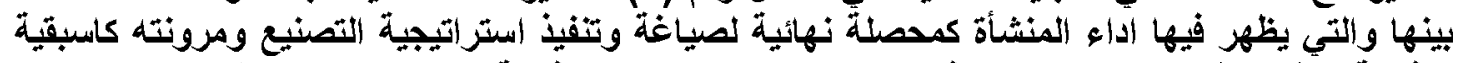

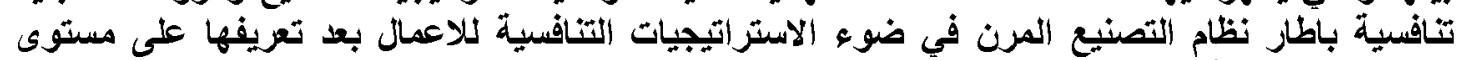
استراتيجية المنشأة. 


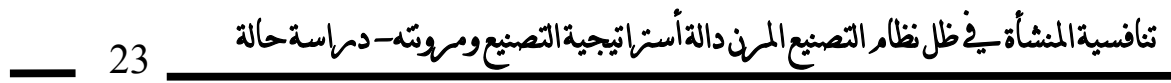


تفسر استراتيجية التصنيع ومرونته المستمدة من اعمال المنثأة واستراتيجيتها باطرار نظام التصنيع

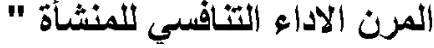

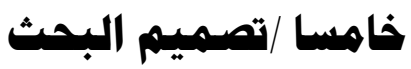

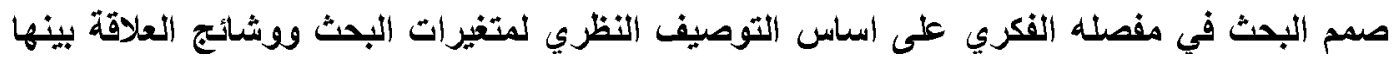

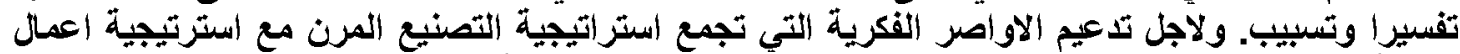

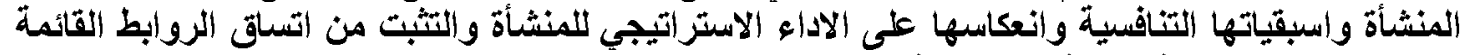

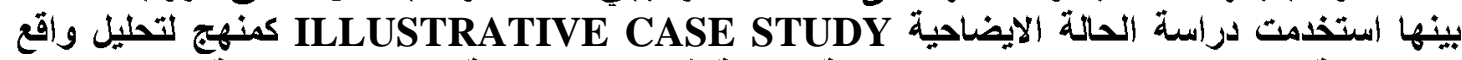

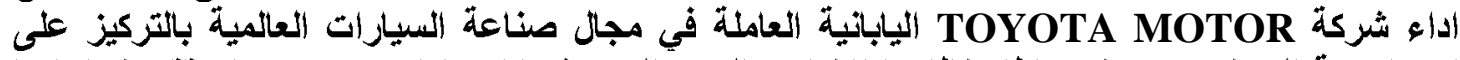

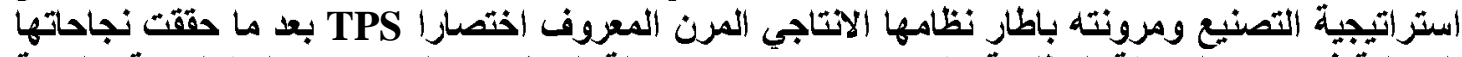

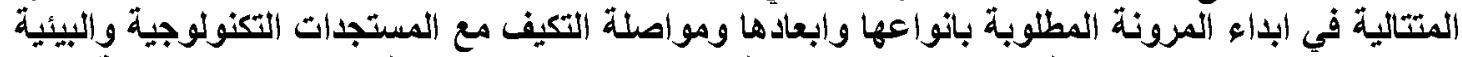

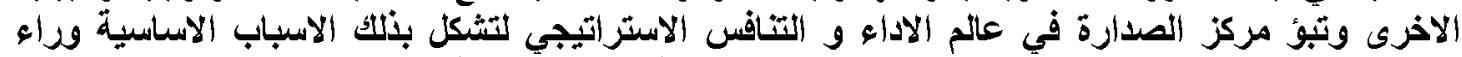

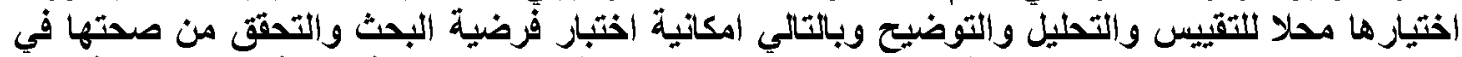

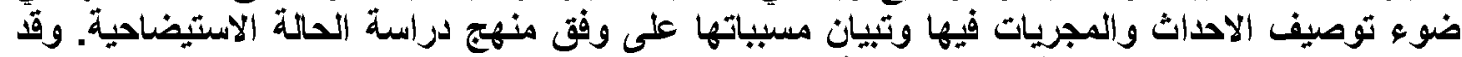

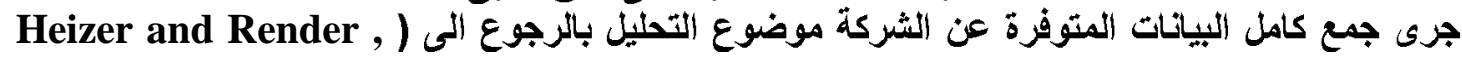
(2009 :534-536;Jacobs,et.al.,2009:405)

\section{الضشمون الفكري لمتغيرات البحث/ توصيف وروابط}

\section{Manufacturing Strategy:}

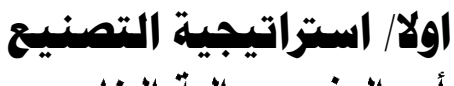

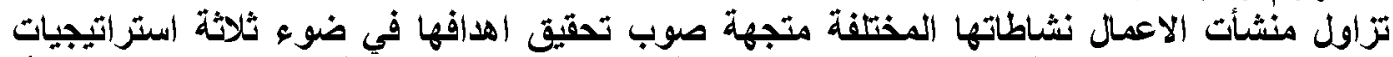

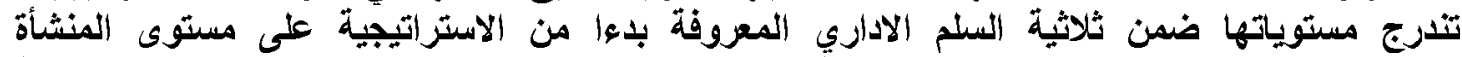
Corporate Strategy

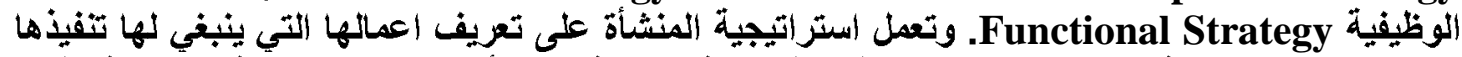

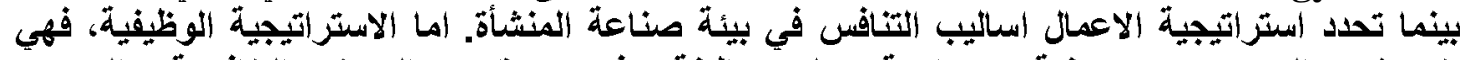

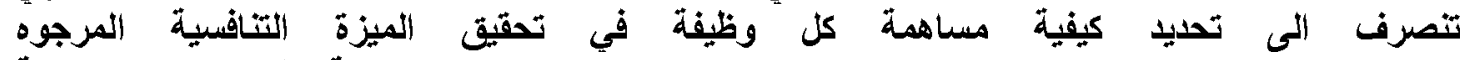
(Krajewski,et.al.,2010:9-10;Slack,et.al.,2004:67)

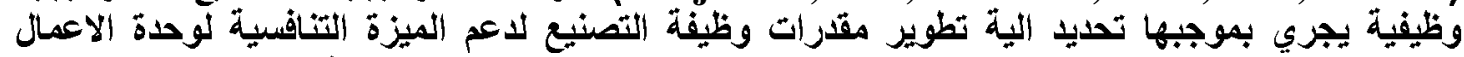

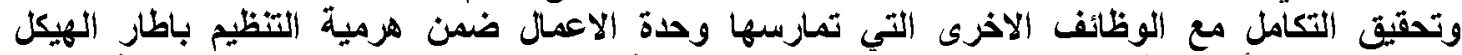

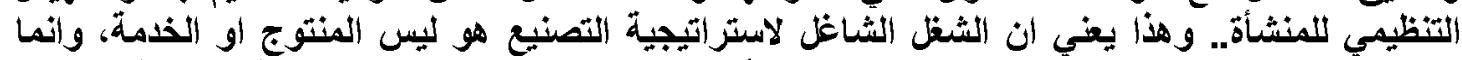

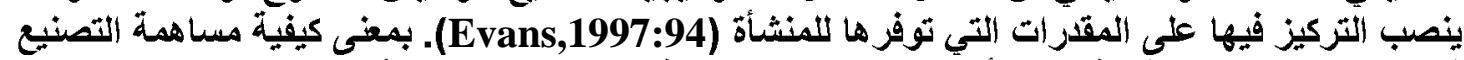

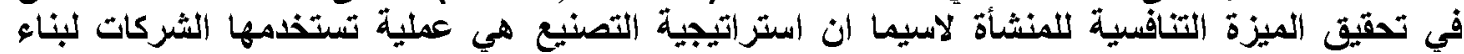

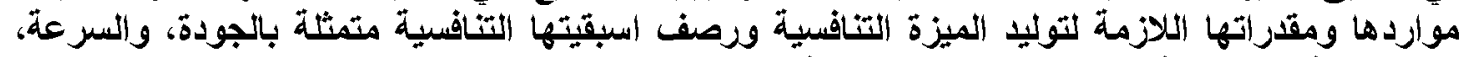

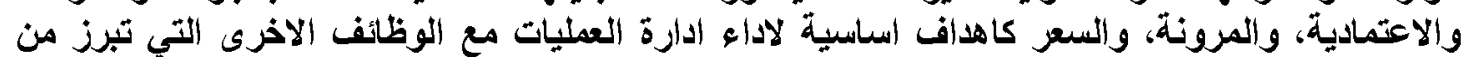

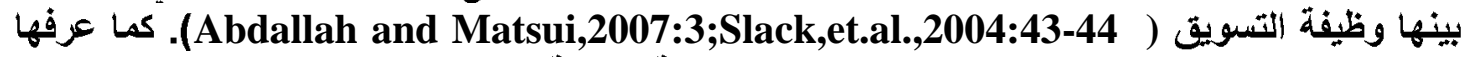
(Bates,et.al. ,1995)

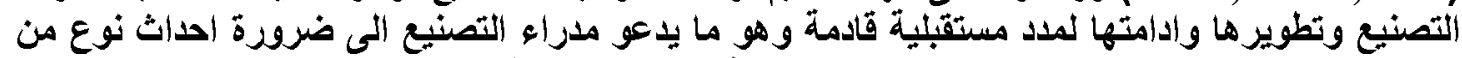

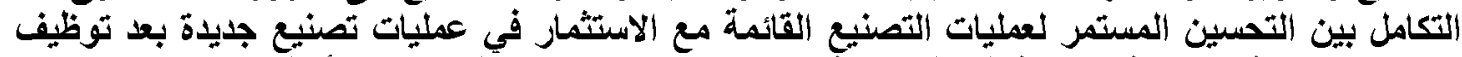

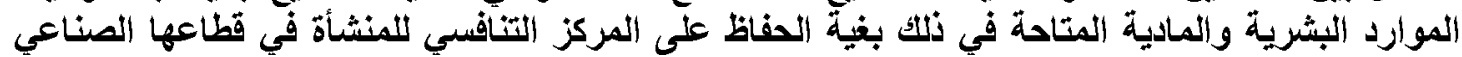

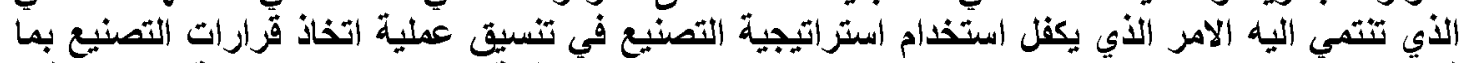

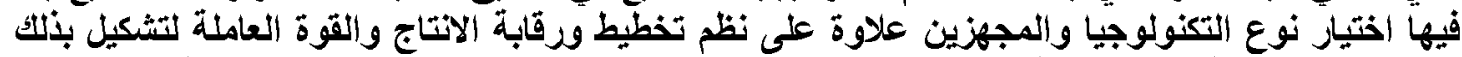

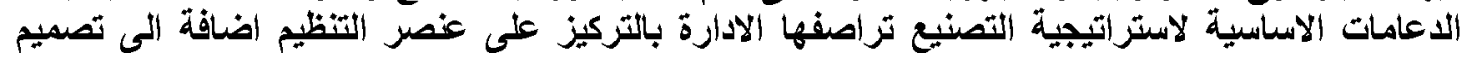


وطالما ان استراتيجية التصنيع كاستراتيجية وظيفية تنساب في صياغتها واعدادها على وفق التئن التناغم

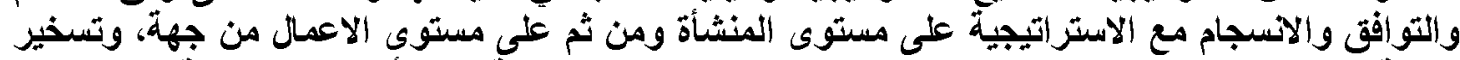

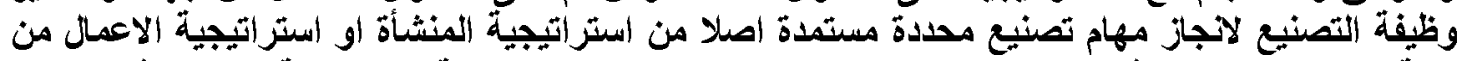

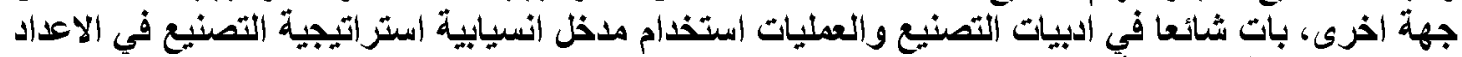

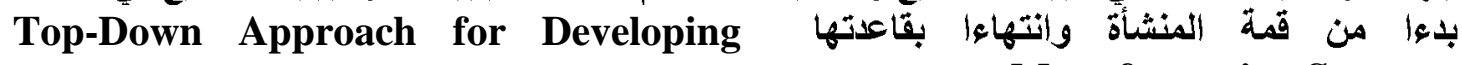
Manufactturing Strategy

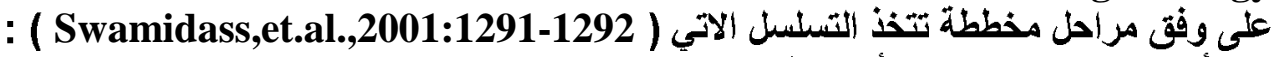

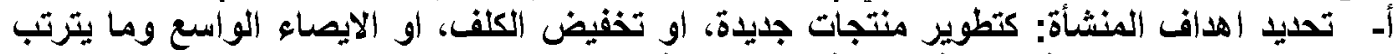

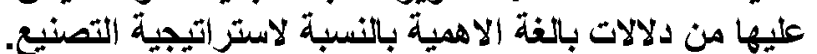

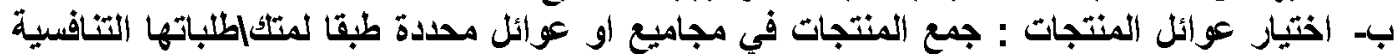

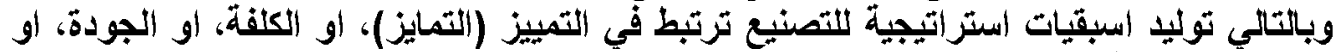

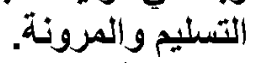

جـ تقصي الظروف الخارجية : التركيز على متطابات السوق ومعطيات التنافس فيه استنادا الى مدخلات

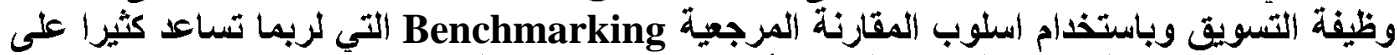

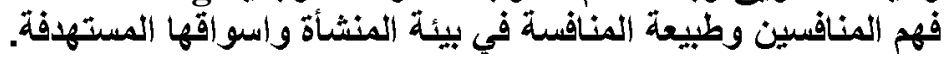

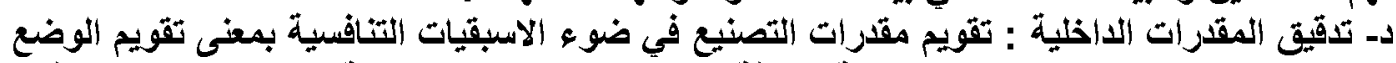

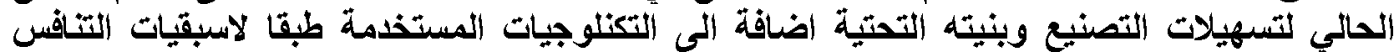

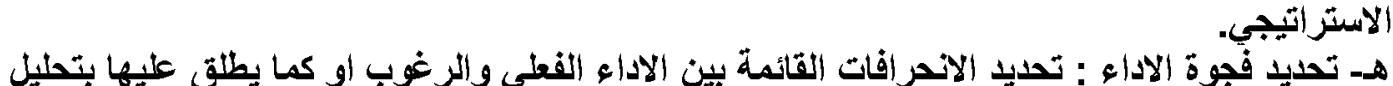

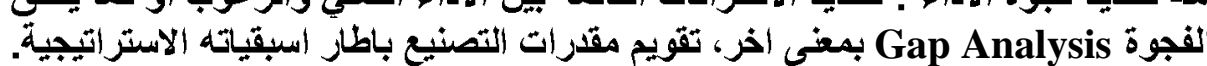

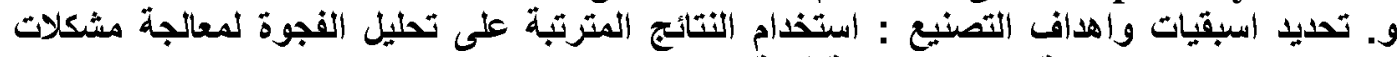

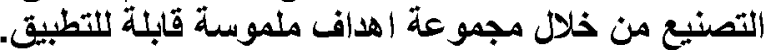
ز- اختيار استراتيجيات التصنيع : تزجمة الاهداف المحددة في الخطوة السابقة (و) الى خطط تصنيع محدة.

ويمكن التعبير عن خطوات اعداد استراتيجية التصنيع المذكورة على وفق مدخل انسيابية استراتيجية

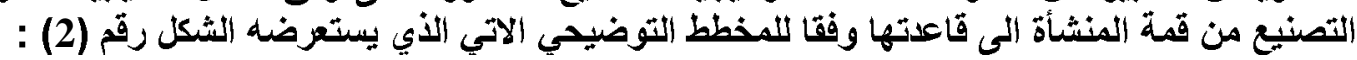


الشكل (2) اعداد استراتيجية التصنيع على وفق مدخل الانسيابية من قمة المنشأة الى قاعتتها

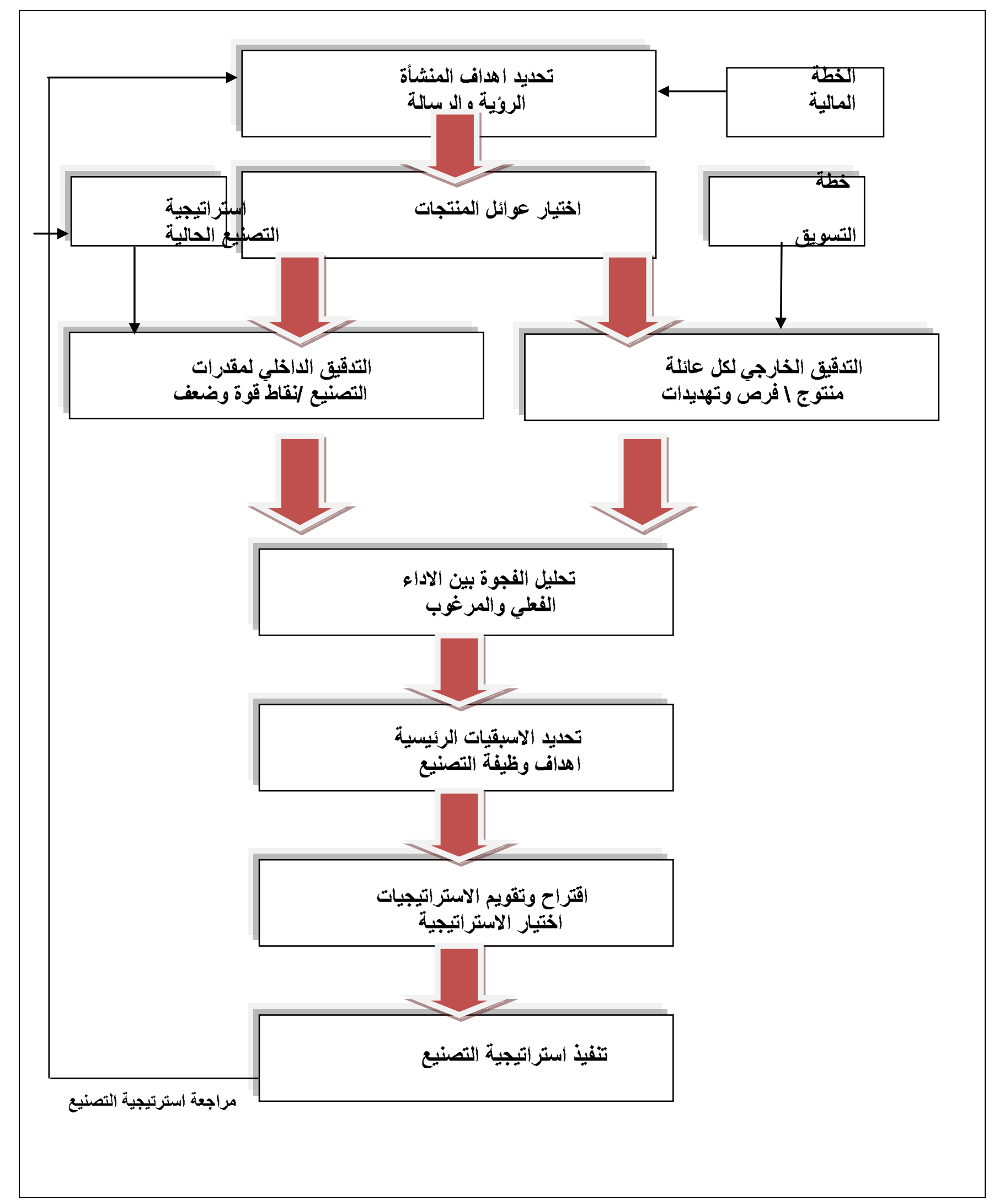

Source : (Swamidass,2001:1292) 


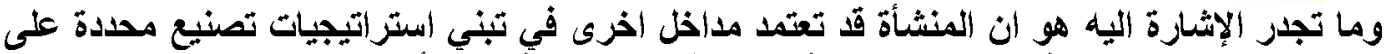

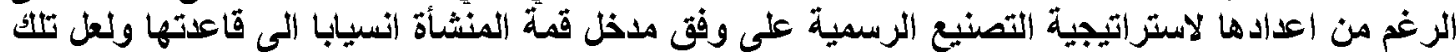

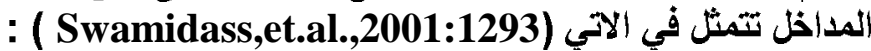

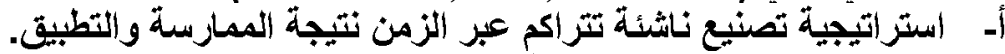
ب- برامج تحسين التصنيع والعملية. ج- برامج تطوير مقرات التصنيع الجوهرية.

ويسود الاعتقاد بان تتفيذ استراتيجيات التصنيع المحكمة يعتد على الية العلاقة بين قرارات التصنيع

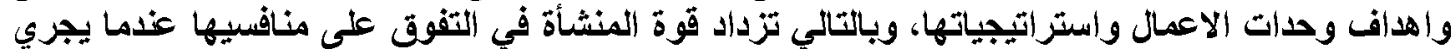

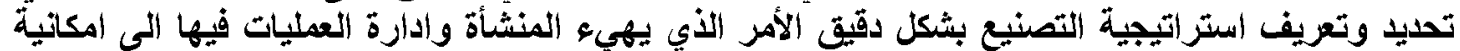

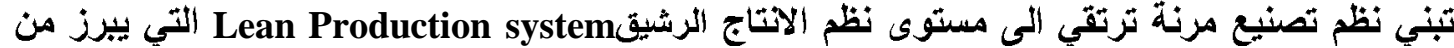

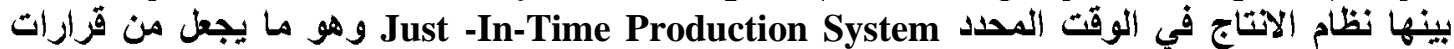

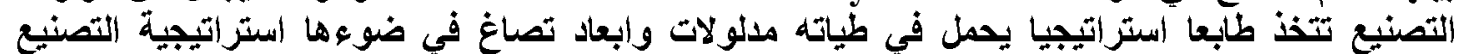

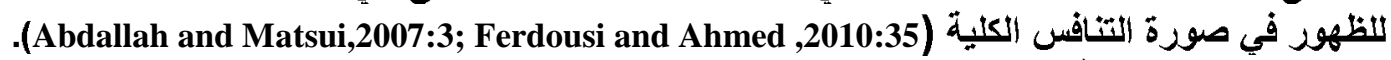
ب. ابعاد استراتيجية التئنية التصنيع

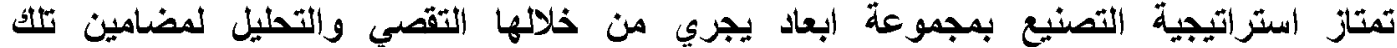

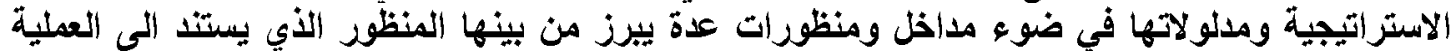
Process- Based perspective

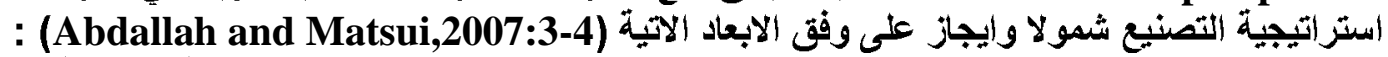

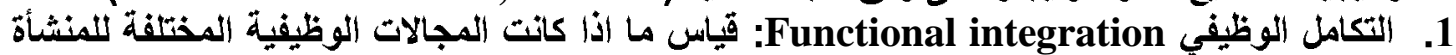

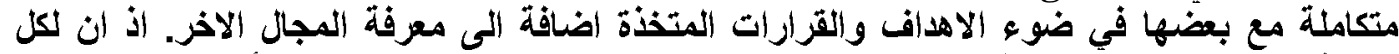

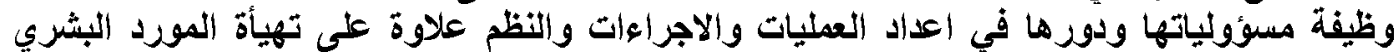

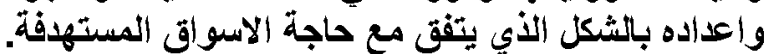

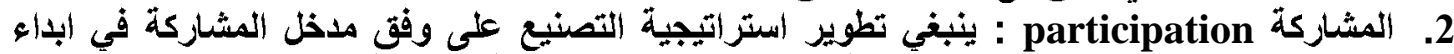

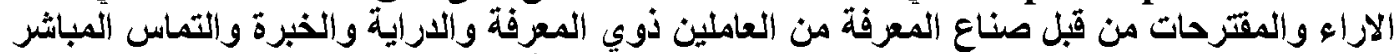

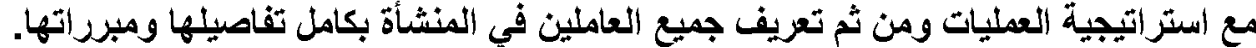
3. استثراف التكنولوجيا الجنيدة Anticipation of new technology : بمعنى التنبؤ بالتكنولوجيا:

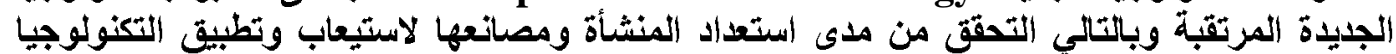

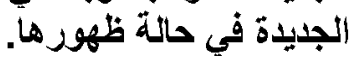

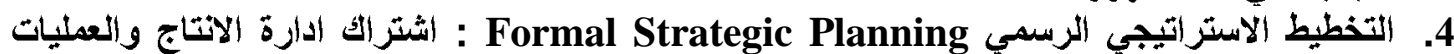

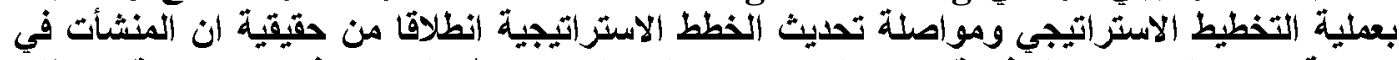

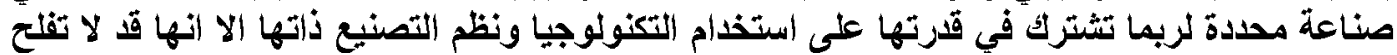

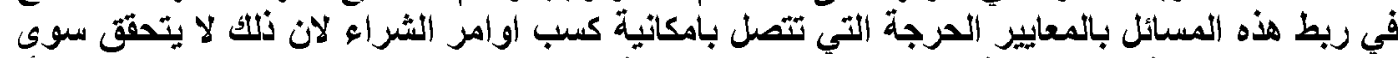

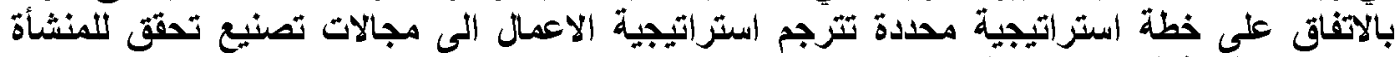
ميزتها التناقسية في عالم التنافس. 
5inking Manufacturing Strategy ربط استراتيجية التصنيع باستراتيجية الاعمال " With Business Strategy

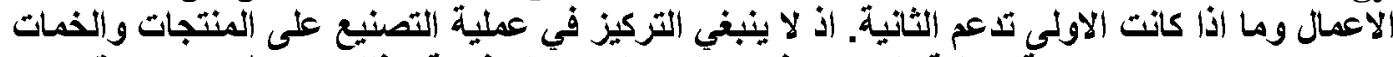

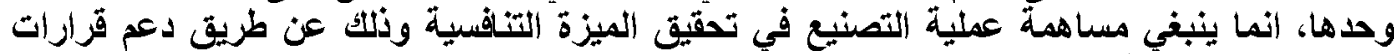
التصنيع لاستر اتتيجية الاعمال.

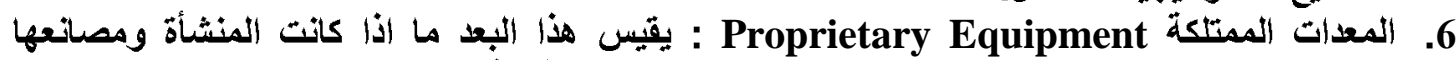
تسعى اللى تطويز معداتها داتخليا كمصدر من مصادر ميزتها التنافسية.

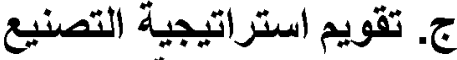

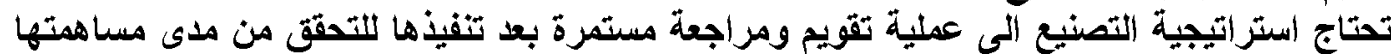

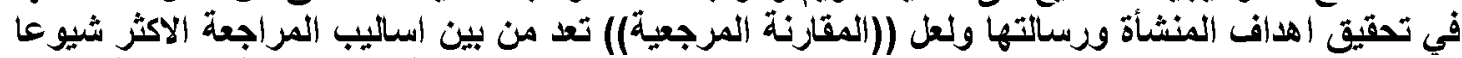

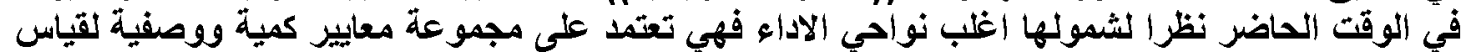

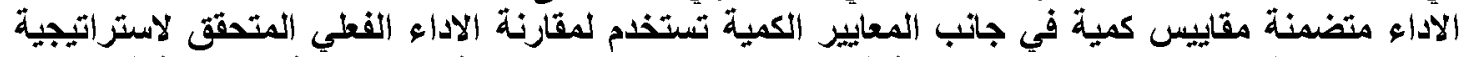

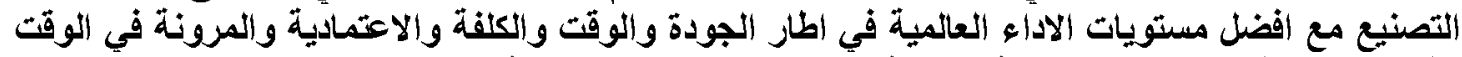

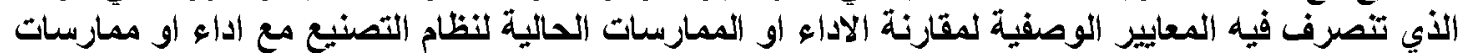

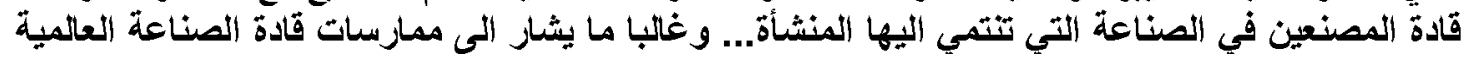

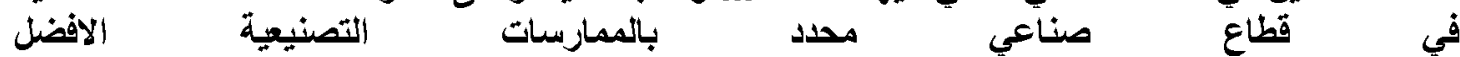
Best Practices

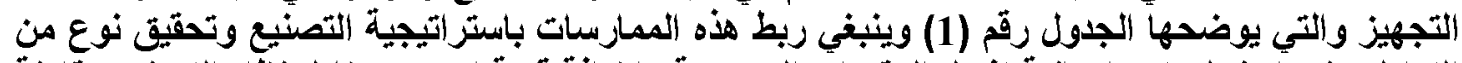

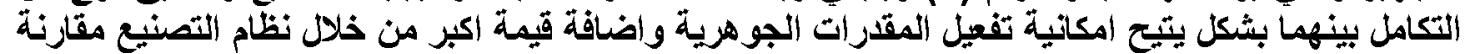

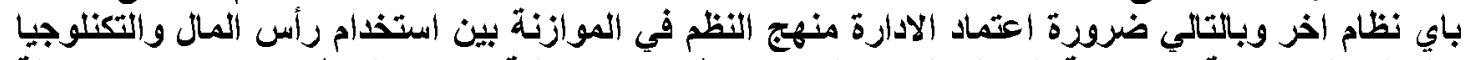

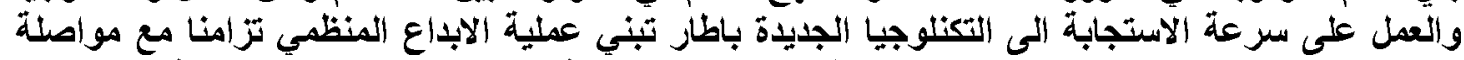

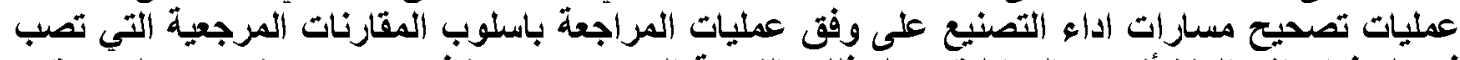

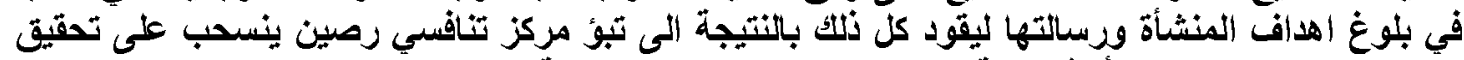

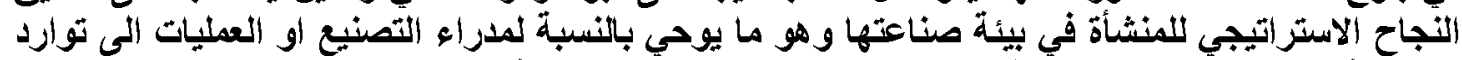

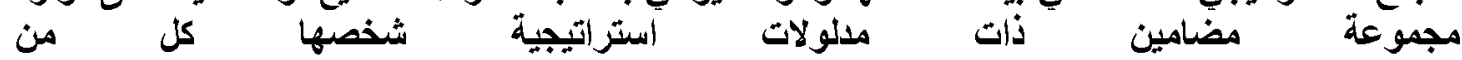
(Emst and young,1998)

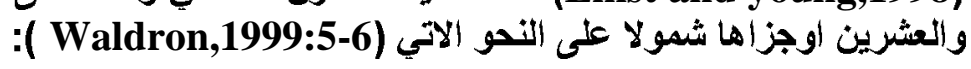

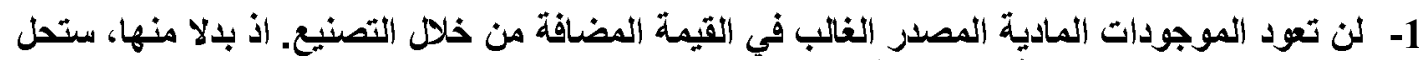

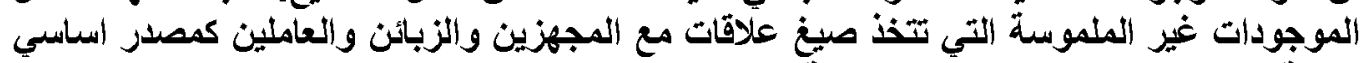

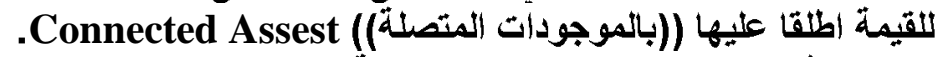

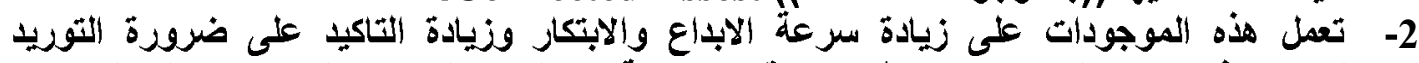

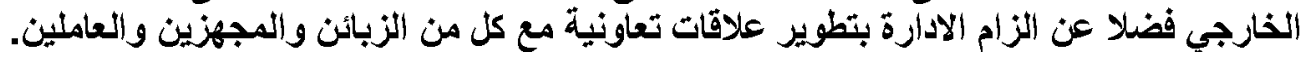

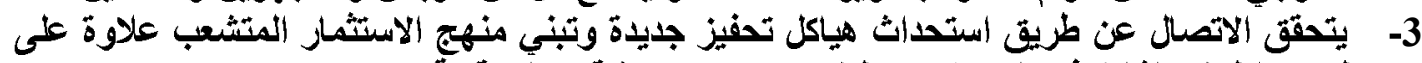
ظهور الطرف الثاته في التعاملات وطيف واسع من الاتفاقات التعاقدية. 
الجدول (1) ممارسات التصنيع الافضل

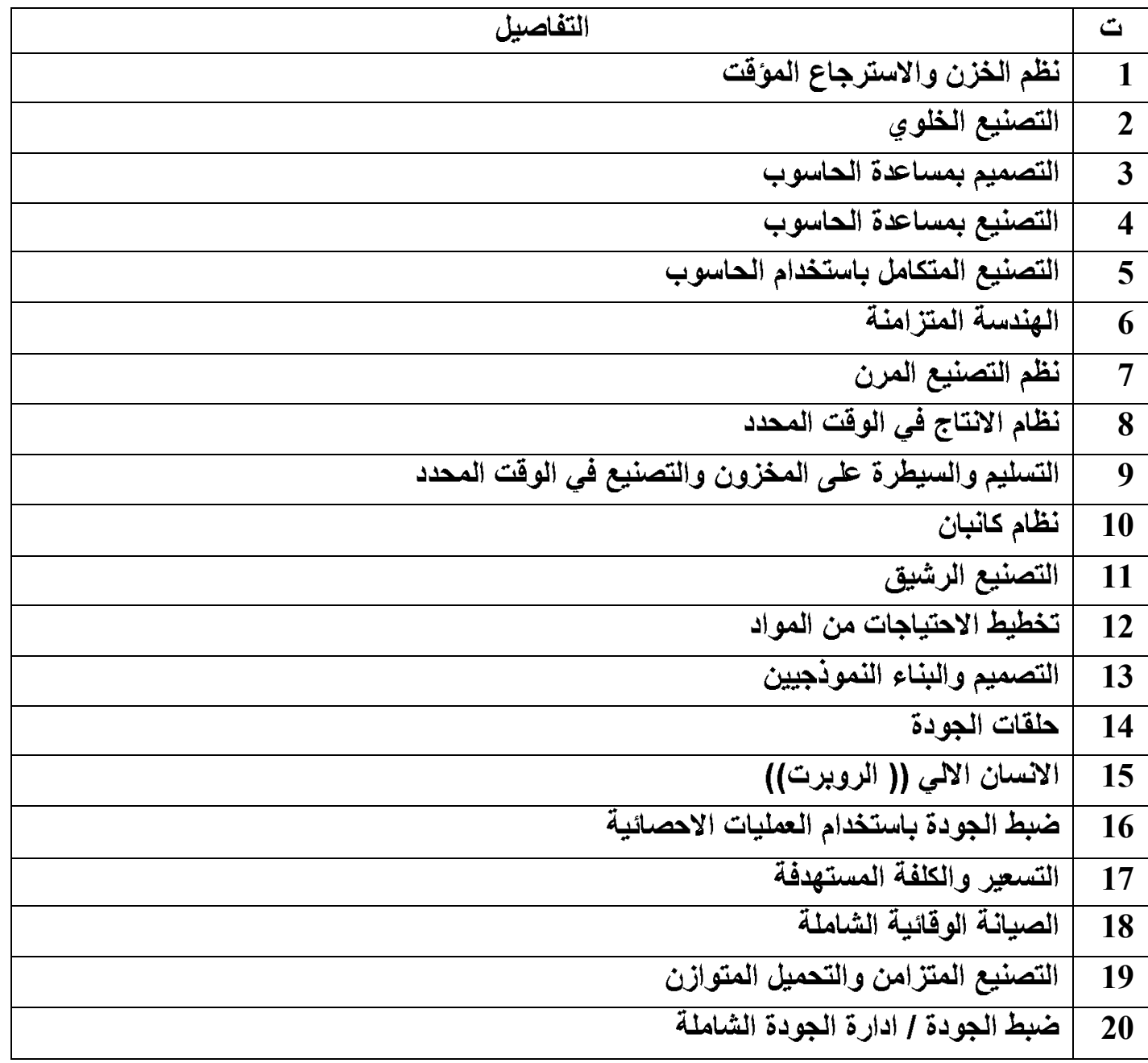

Source: (Waldron , 1999 : 6 )

شanufacturing Flexibility : ثانيا / هرونة التصنيع

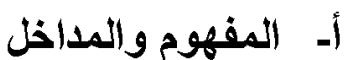

تعد مرونة التصنيع من اكثر الاهداف التي يصعب على المنشأة تحقيقها، فهي مفهوم متعدد الابعاد يتصل

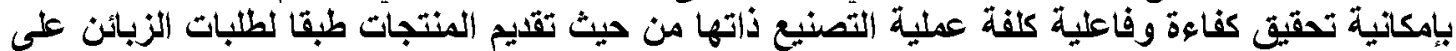

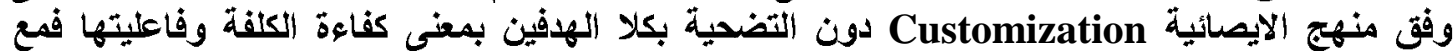

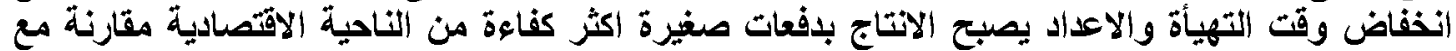

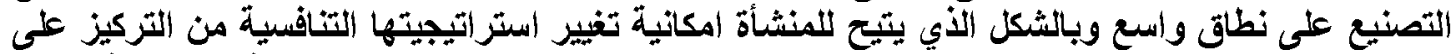

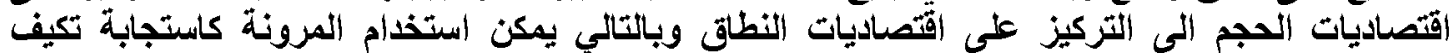

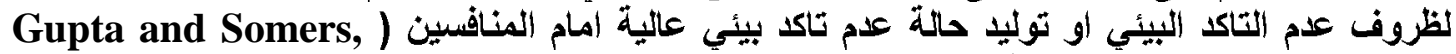

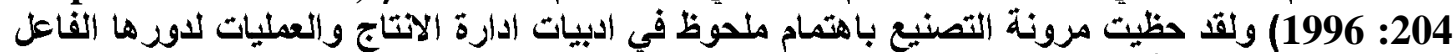

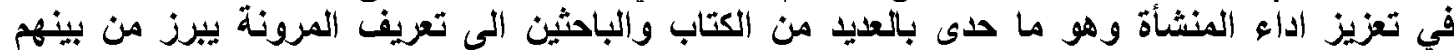
(Gupta, 1994)

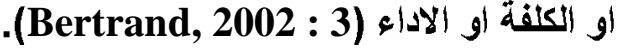


كما عرفها اخرون على انها قدرة نظام التصنيع على الاستجابة العريعة والفاعلة من حيث الكلفة الى الى

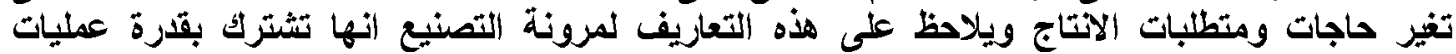

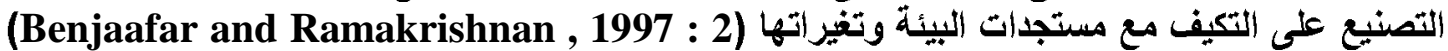

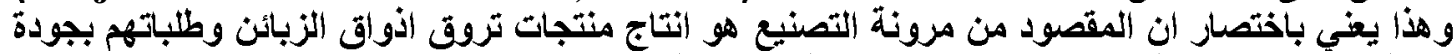

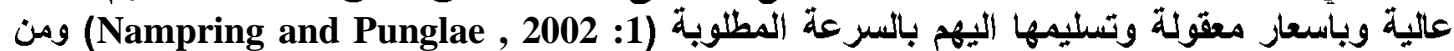

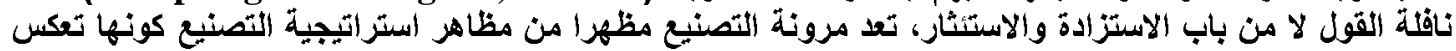

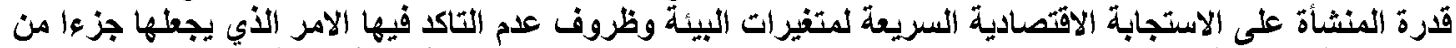

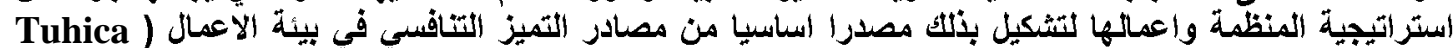

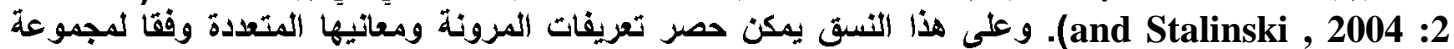

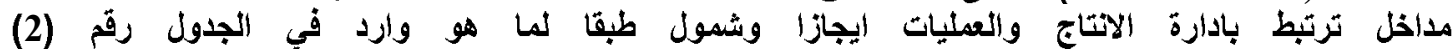
: ( Shivana and , et.al.,2006 :4;Nampring and Punglae , 2002 :2) الجدول (2) مداخل المرونة وتعريفاتها

\begin{tabular}{|c|c|c|c|}
\hline تعزيف المرونة & \multicolumn{2}{|c|}{ 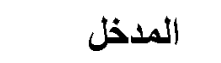 } & $ت$ \\
\hline القدة على انتاج اجزاء مختلفة دون الحاجة الى تجايد ادوات التصنيع & 1 & \multirow{3}{*}{ 可 } & \multirow{3}{*}{1} \\
\hline الذياس انتاج المنتجات الجديدة في التحول من انتاج المنتجات على خطوط الانتاج القايمة & ب & & \\
\hline القلرة على تغيير جدول الانتاج او تعديل الاجزاء او مناولة اجزاءء متعددة. & ج & & \\
\hline القرة على انتاج منتجات فريدة من نوعها حسب طلبات الزبائن ويكفاءة عالية. & & التشغيلي & 2 \\
\hline القدرة على استغلال الابعاد المختلفة لسرعة التسليم. & & 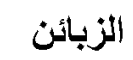 & 3 \\
\hline قرةة الثركة على عزض تثكيلة واسعة من المنتجات الى زبائنها. & & الاستز اتي & 4 \\
\hline القرة على زيادة او تخفيض علاخ مستويات الاتتاج بسرعة او تحويل الطاقة من منتوج & & الطاقة & 5 \\
\hline
\end{tabular}

Source : ( Shivan and ,et.al.,2006:4;Nampring and Punglae,2002 :2) 


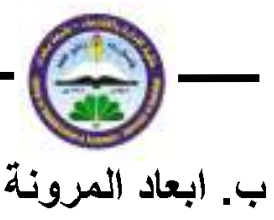

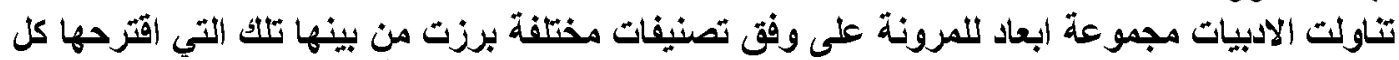

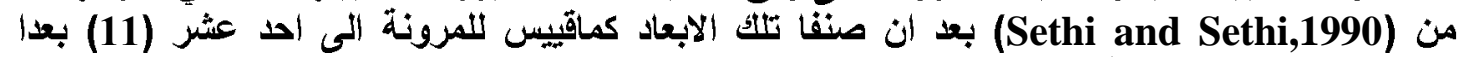

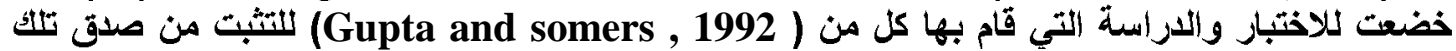

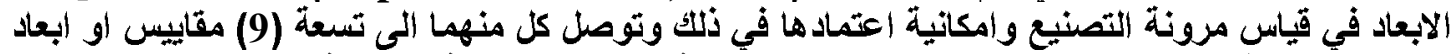

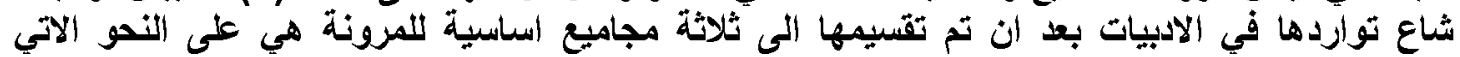

: (Gupta and somers ,1996:208-209;shivan and ,et.al.,2006:4-5)

Basic Flexibilities: المرونات الاساسية المرونة

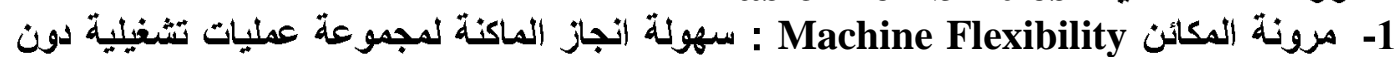

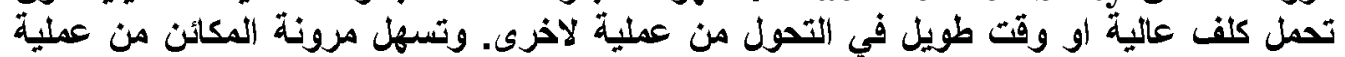

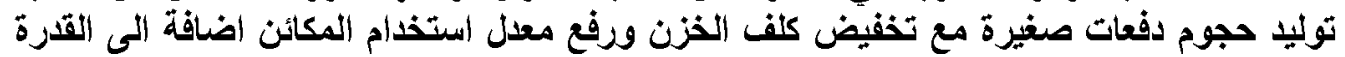

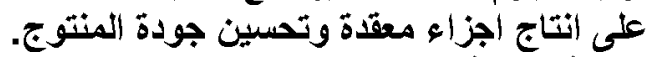

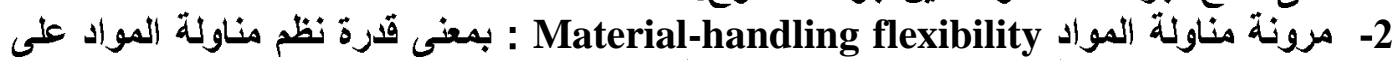

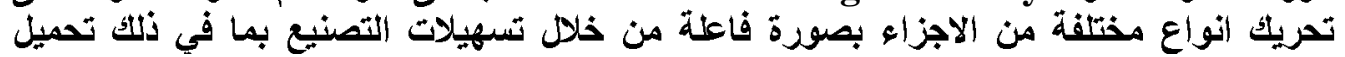

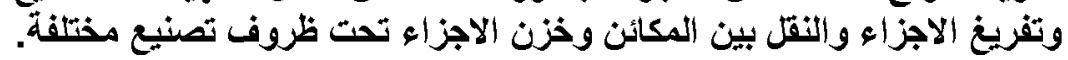

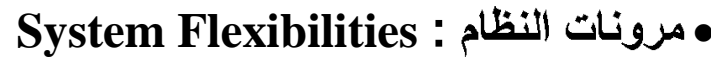

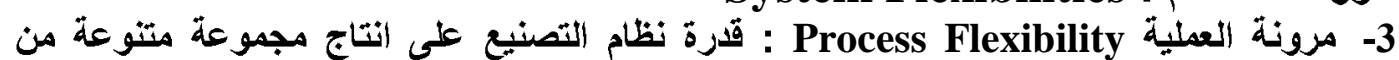

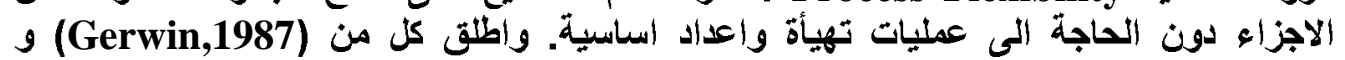

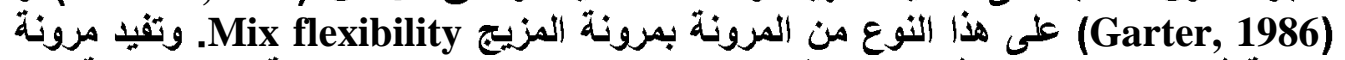

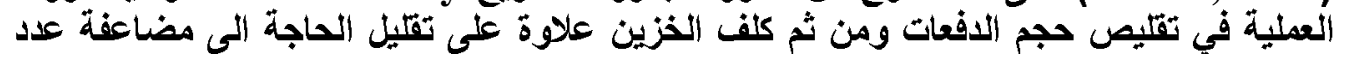
|المكائن.

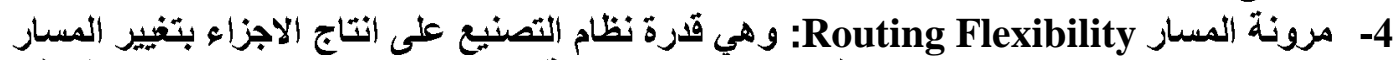

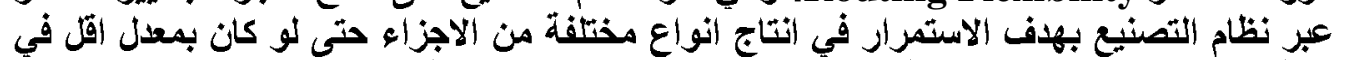

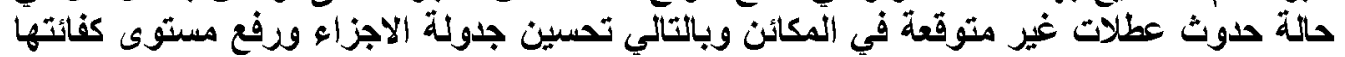
عبر تحسين موازنة عمليات تحميل المكائن فئن فئن 5- مرونة الحجم Volume Flexibility: قدرة فينة نظام التصنيع على مواصلة العمل وتحقيق الارباح بمستويات مختلفة من المخرجات مما يتيح امكانية تعديل الانتاج على على مدئ موامى واسع.

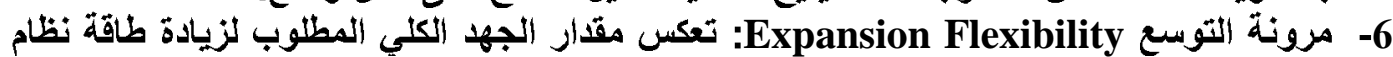

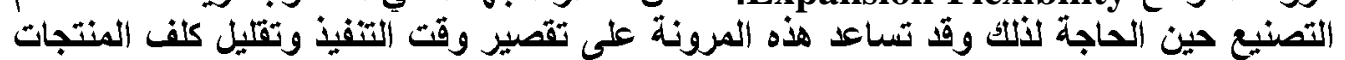

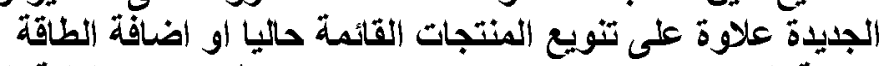

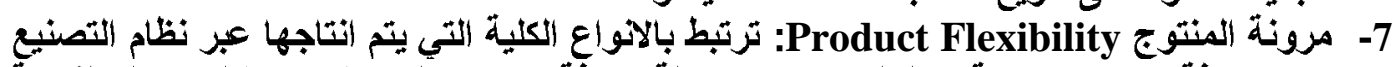

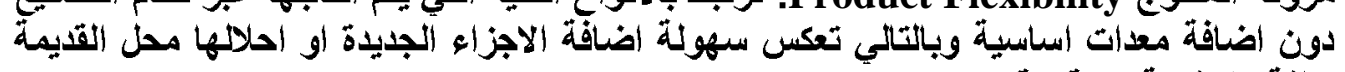

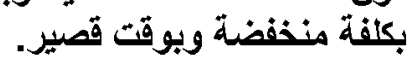

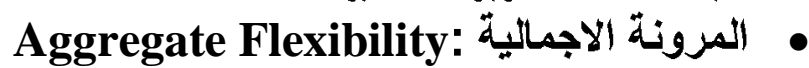

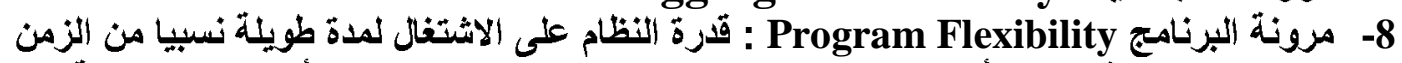

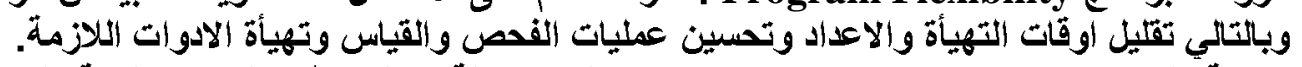

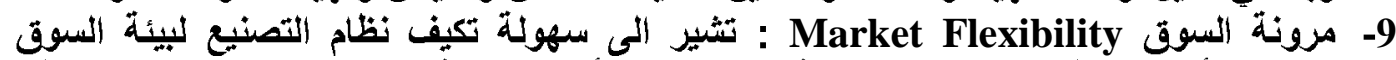

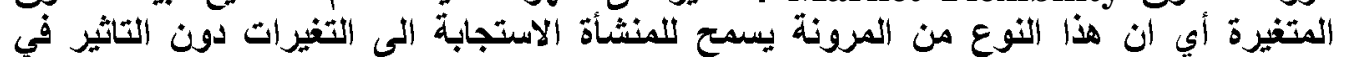

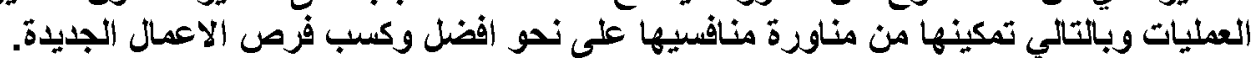


ج - فوائد المرونة:

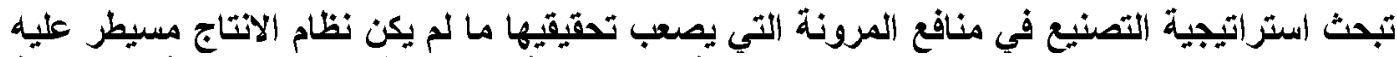

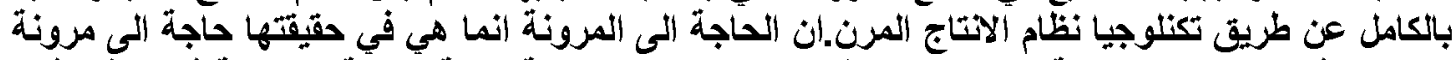

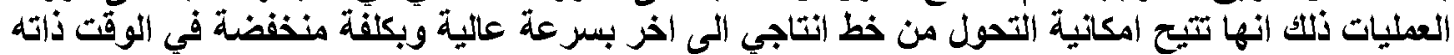

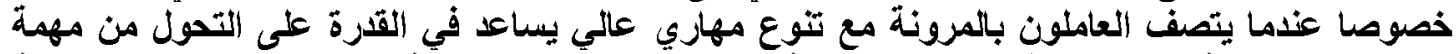

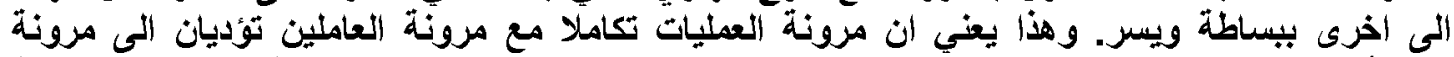

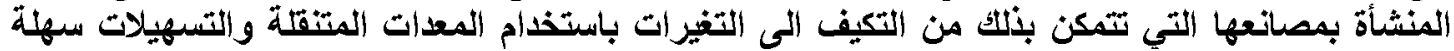

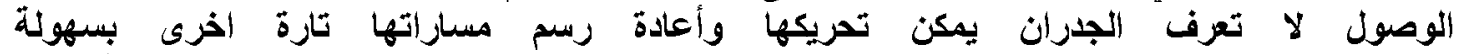
(Shivan and, et.al.,2006 : 8 ; Nampring and punglae , 2002 : 3 )

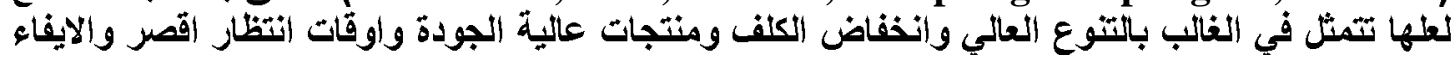

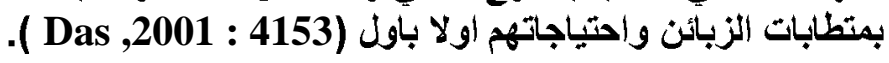

Flexible Manufacturing System, FMS : ثالثا / نظام التصنيع المرن

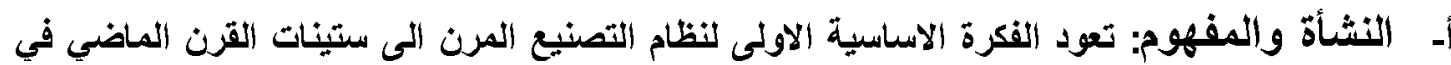

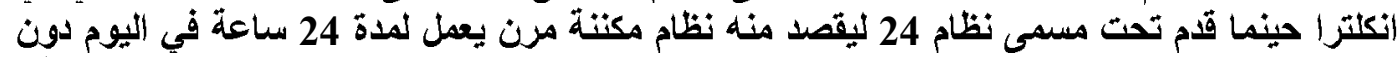

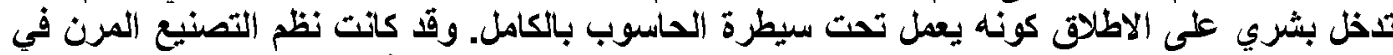

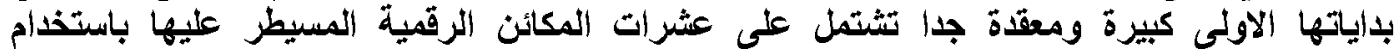

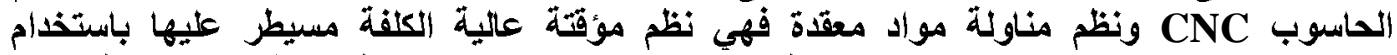

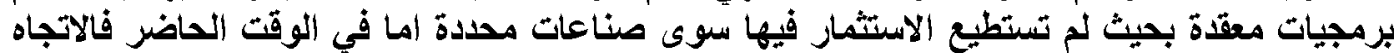

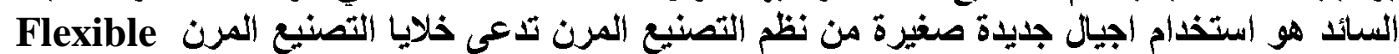
زاد Manufacturing Cells, FMC

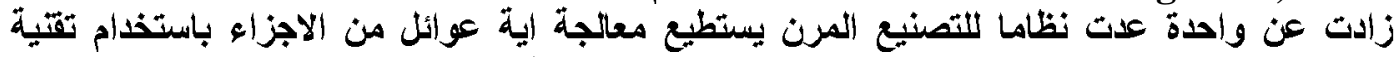

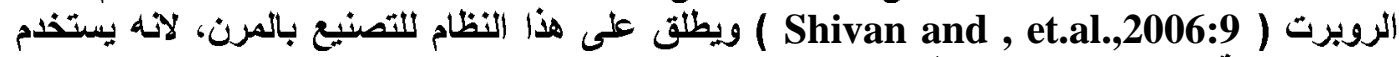

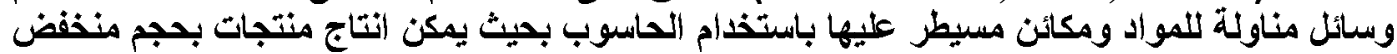

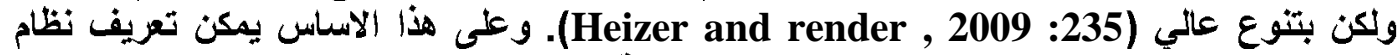

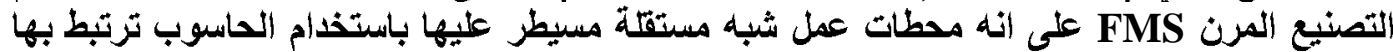

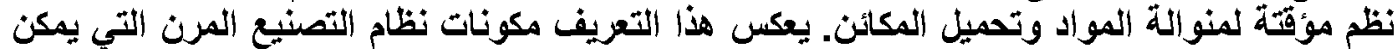
وصفها بايجاز دال ومعبر على النحو الاتي (Slack,et.al.,2004:251;Jacobs,et.al.,2009:733)

1. محطات عمل مسيطر عليها باستخدام الحاسوب تضم مكائن مسيطر عليها رقميا NC او مراكز عمل عالية التعقيد تنجز عمليات مكنتة متعددة.

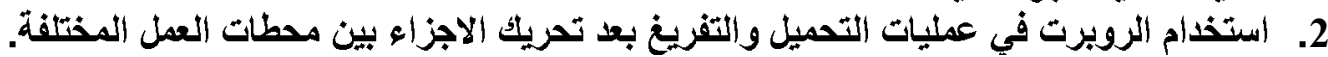

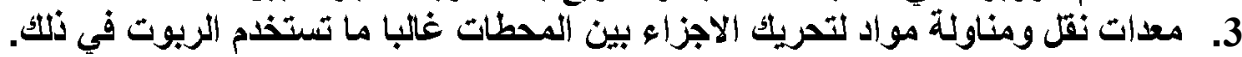

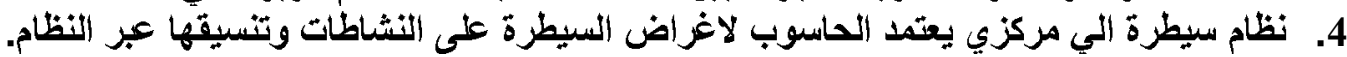

ب- الهاف وغايات نظام التصنيع المرن :- تتمثل الاهداف الاساسية لنظام التصنيع المرن وغايتاته : بالاتي (9): Shivan and , et.al.,2006 )

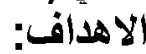

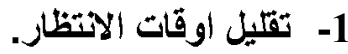

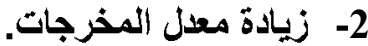
3- 3- استغلال معدل استخدام المكائن.

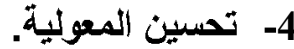
5- 5 ت تقليل مستويات الخزين.

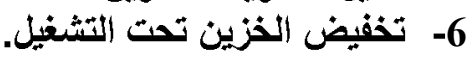

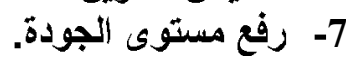




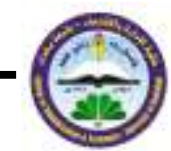

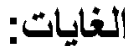

1- ت تقليل الكلف عن طريق الاستخدام الافضل لمعدات الانتاج.

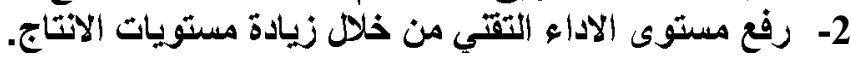

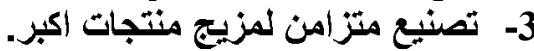

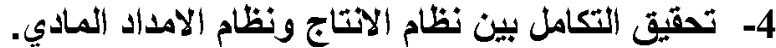

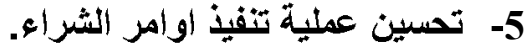
6- تعزيز تنافسية المنشأة ورفع مستوى الجودة تحسينا لصورتها في السوق.

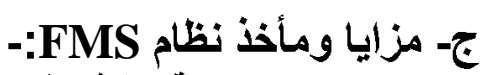

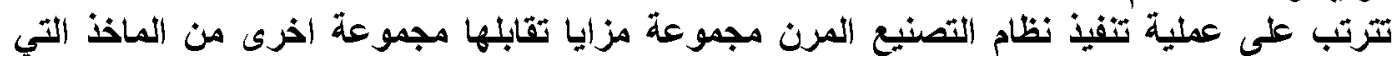
تمكن ايجاز ها على النحو الاتي (Slack,et.,2004:255; Shivan and ,et.al.,2006:10-11):

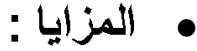

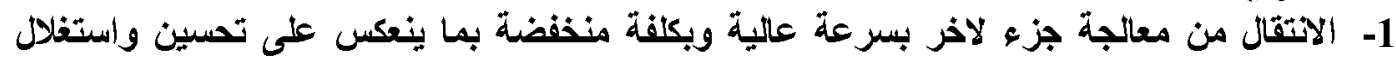
واستخام راس المال. 2- 2 - انخفاض كلف العمل المباشر بسبب انخفاض عدد العاملين. 3- أنفاض حجم الخزين لاقة التخطيط والبرمجة. 4- ارتفاع مستوى الجودة بسبب عملية النيطرة المؤقتة. 5- انغفاض كلفة الوحدة الواحدة من المخرجات بسبب ارتفاع الانتاجية باستخام العدد ذاته من

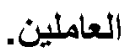

6- الاذخارات المتحققة بسبب العمل غير المباشر وانخفاض عدد الاخطاء وانخفاض حجم المواد التي

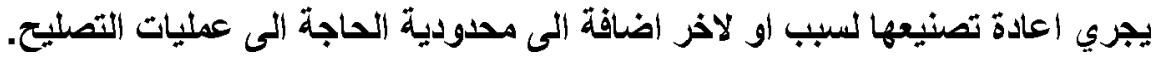

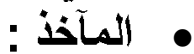
1- القارة المحدودة للتكيف مع تثيير المنتوج او مزيج المنتجات بسبب الطاقة المدودة للمكائن. 3- - يتطب نشاط كثيف يسبق علية التخطيط لتنفيذ النظام. 3-

4- ترافق تنفيذ النظام مشكلات تكنلوجية تتطق بالاختيار الدقيق لاماكن وضع المكونات والدقة العالية

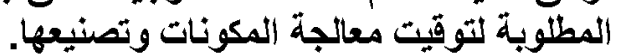

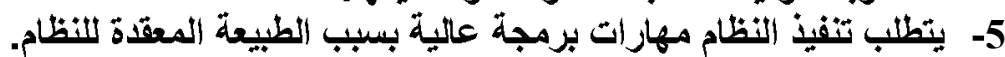

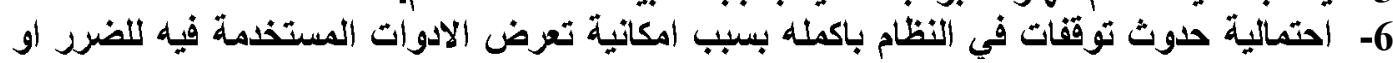
التهشم.

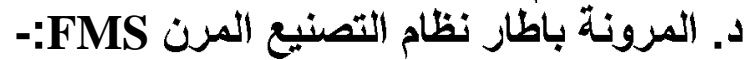

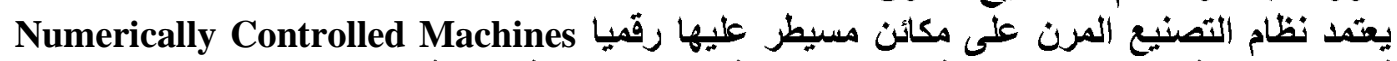

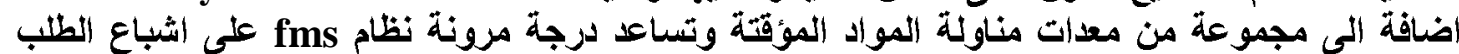

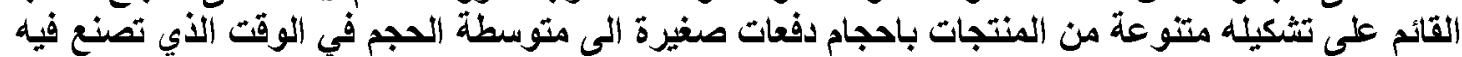

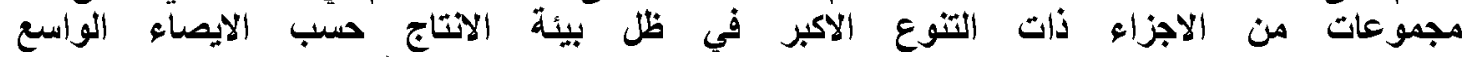
mass-customized production environment

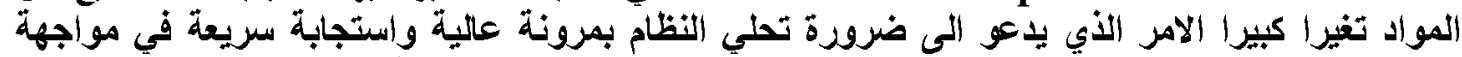

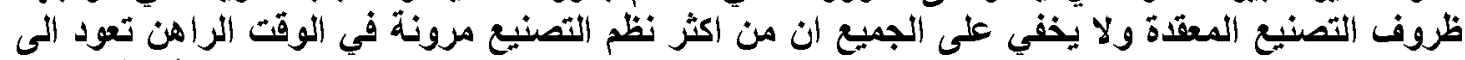

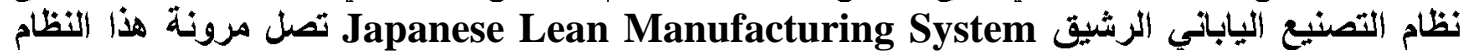
اللى الحد الذي تتطلبه بيئة الاتتاج حسب الايصاء اللواسع لا سيما ان الانتاج الرشيق يعل على وفق الية نظام

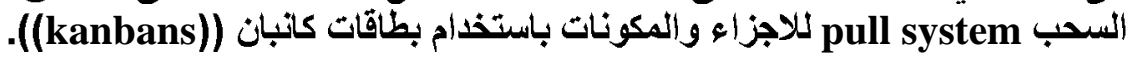




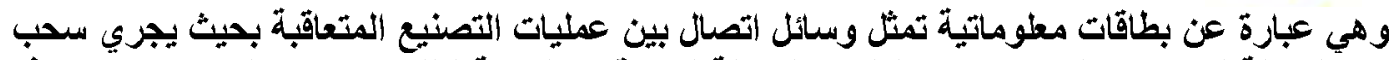

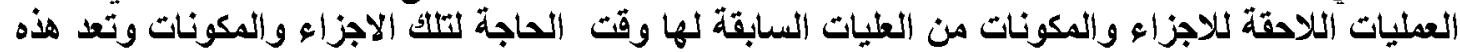

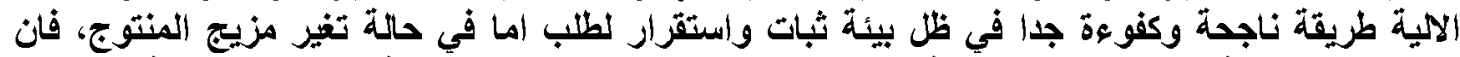

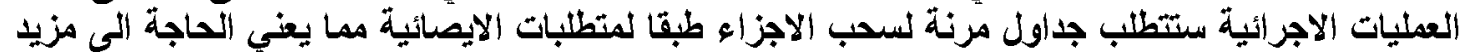

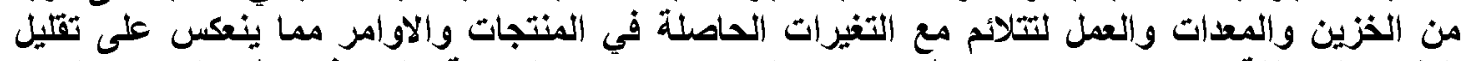

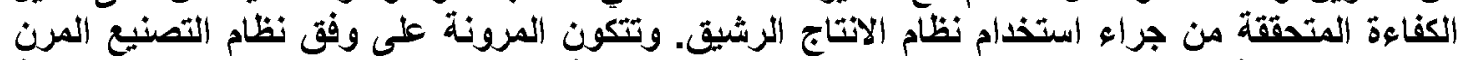
FMS

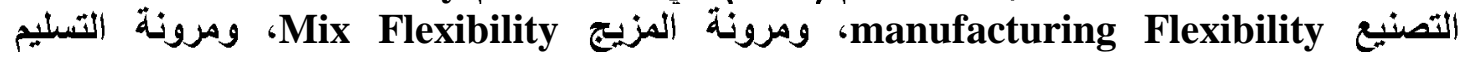
(Roberto and mchean,2002:3;shivan and ,et.al.,2006:1) Delivery Flexibility الثكل ( 3 ) المرونة في ظل FMS

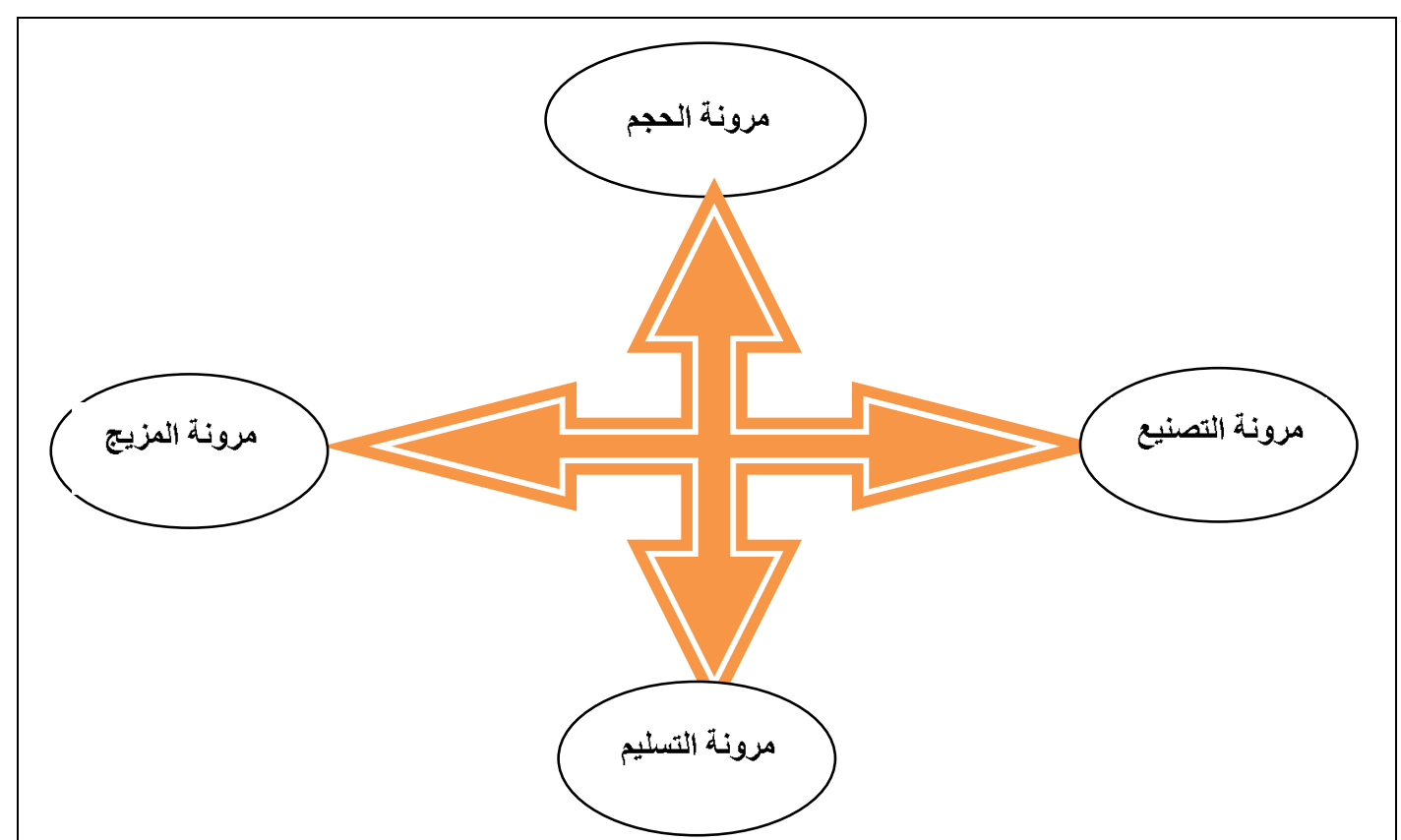

Source :( Shivanand , et.al.,2006:1).

خامسا / اداء المنشأة في ظل مرونة التصنيع : خيارات استراتيجية :- Performance of the Firm under Manufacturing Flexibility: Strategic Choices

يمكن تعريف اداء المنشأة على انه قرةة المنشأة على اشباع حاجات مجموعة الاطراف المتعددة التي

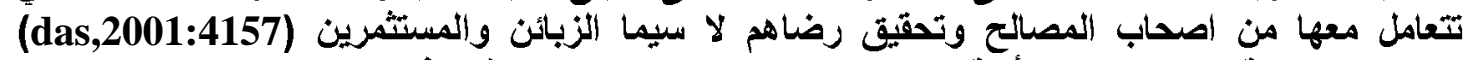

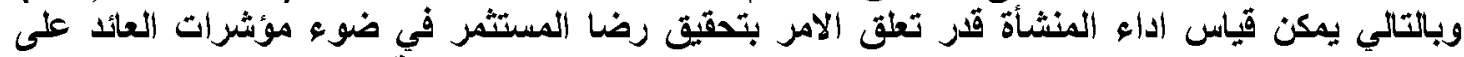

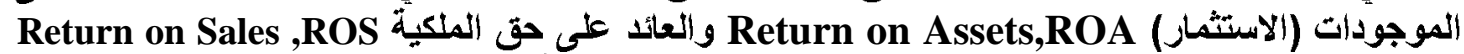

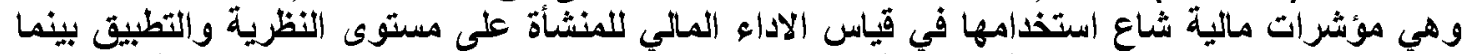

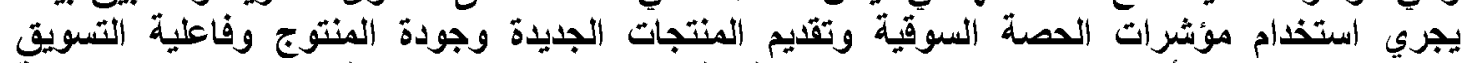

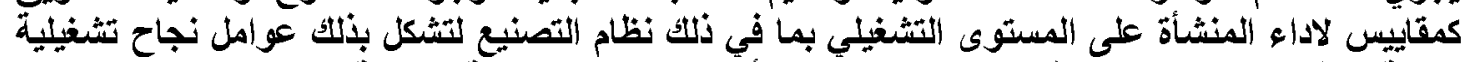

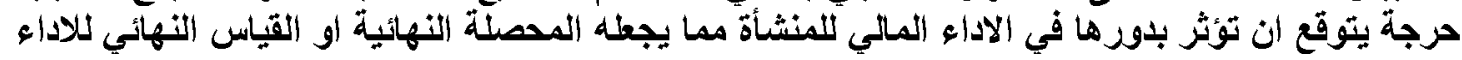
(Gupta and Summers , 1996:209; Das,2001:4157 


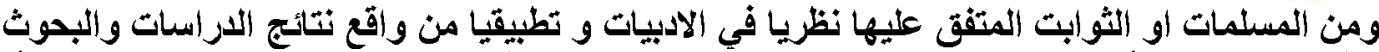

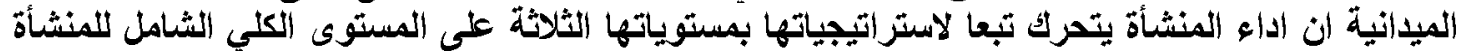

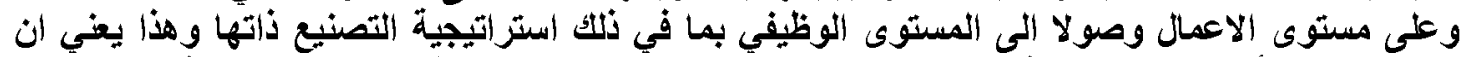

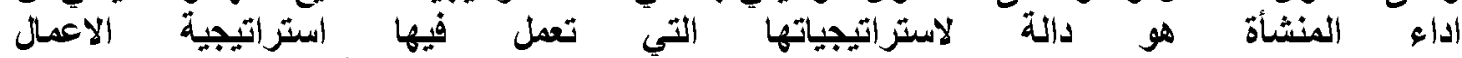

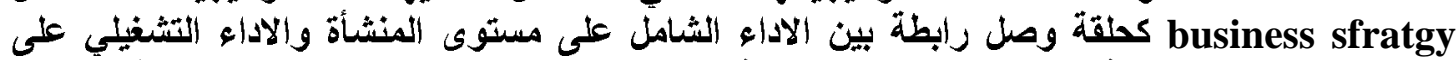

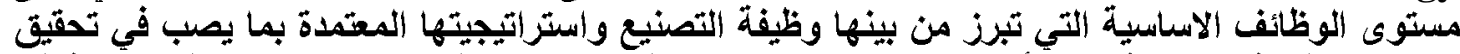

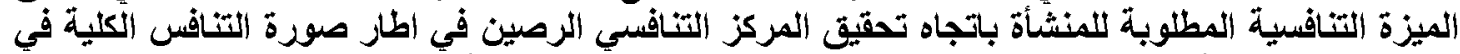

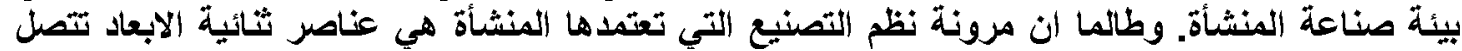

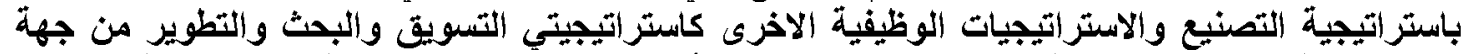

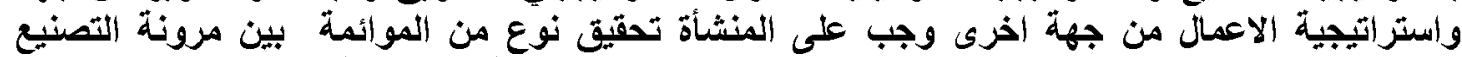

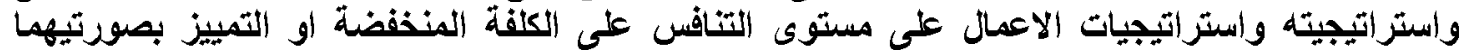

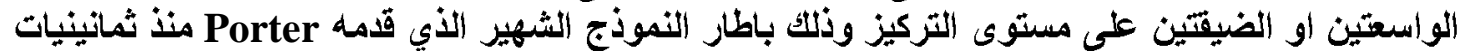

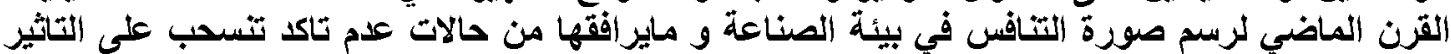

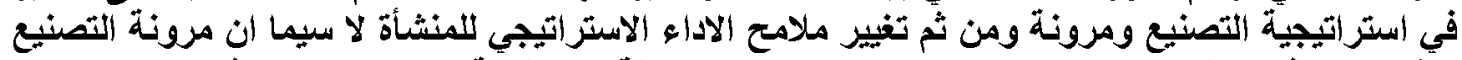

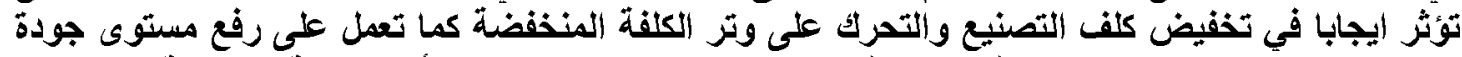

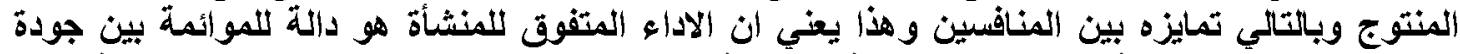

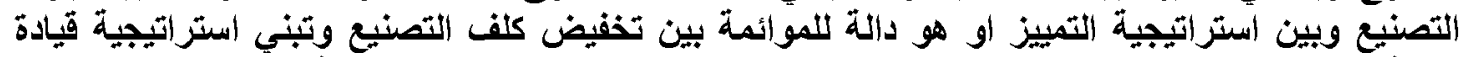

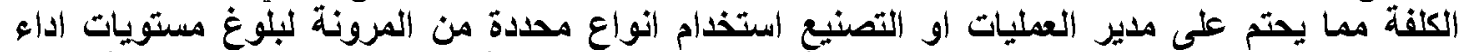

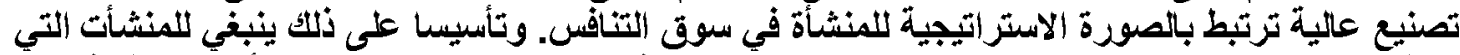

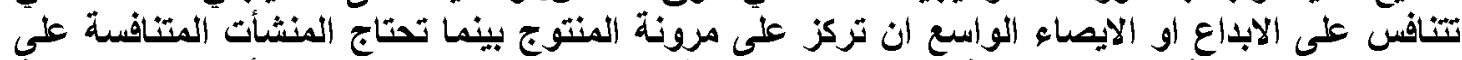

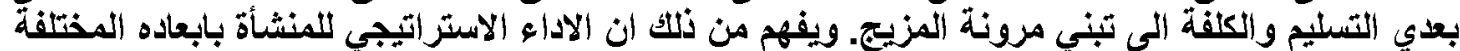

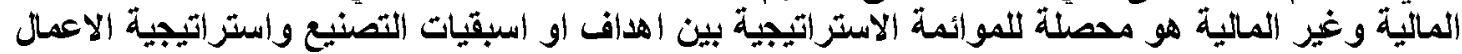

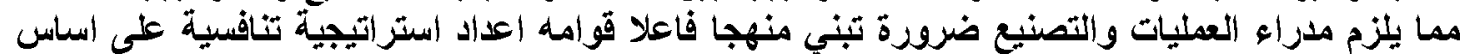

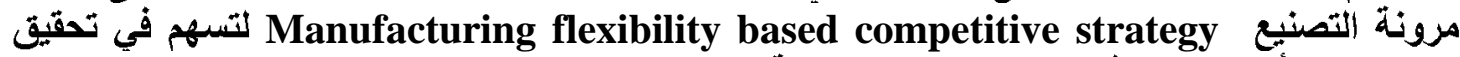

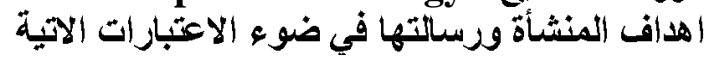

: (das ,2001 :4171-4173;gupta and summers , 1996 :207-210) 1- تقويم قدرات الثراء و التجهيز من حيث الاستجابة والتصنيم.

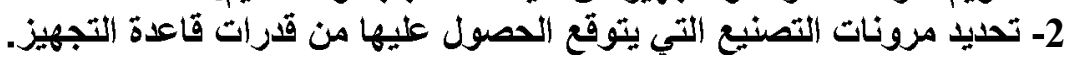

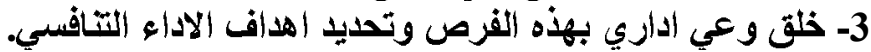

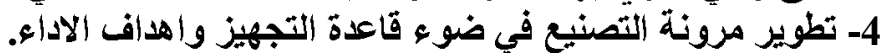
5- تطوير مرونة التصنيع لاغراض في تحقيق الميزة التنافية.

ويستدل من كل ذلك الى رسم صورة واضحة المعالم حول المرونة الاستراتيجية لنظم التصنيع ومنها

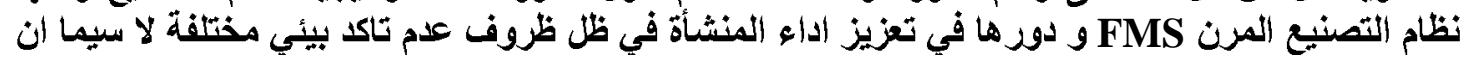

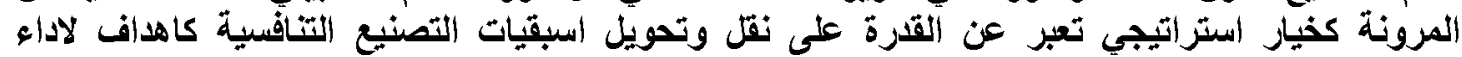

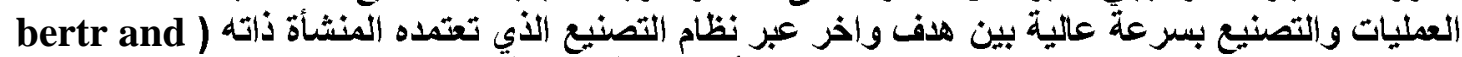

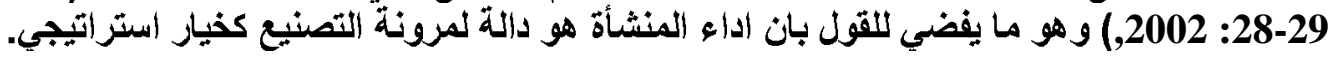




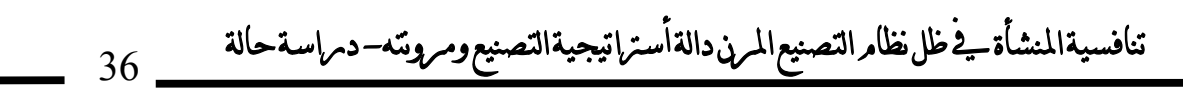

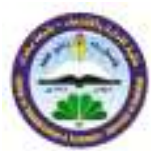

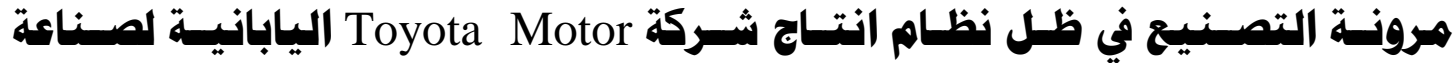

السيارات - هنهج الابداع التنافسي والتفوق الاستراتيجي

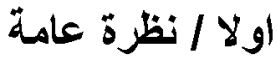

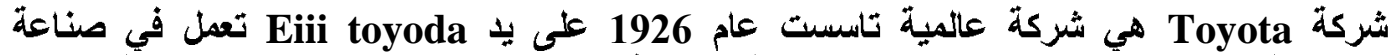

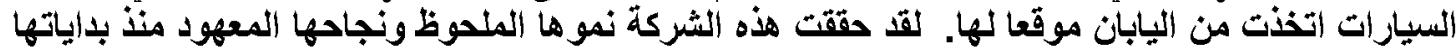

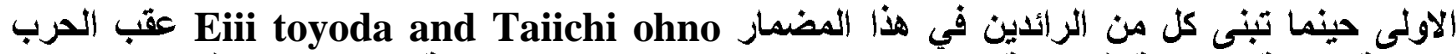

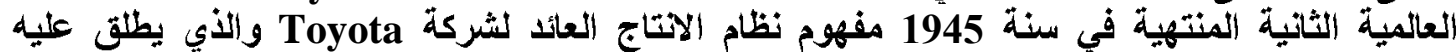

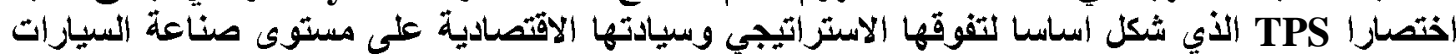

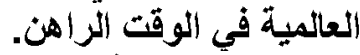

تمتلتك الثركة (80) ثمانون مصنعا تتوزع على مئى (28) ثماني وعشرون بلدا من بلدان العالم طاقتها التصميمية (2-3) مليون مركبة لتثكيل بذلكائ ما نسبته

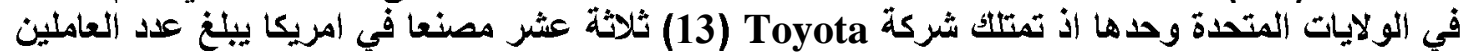

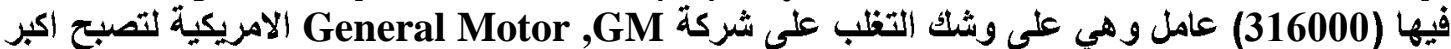

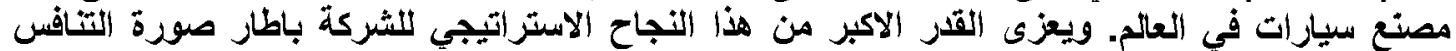

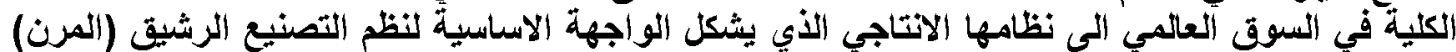

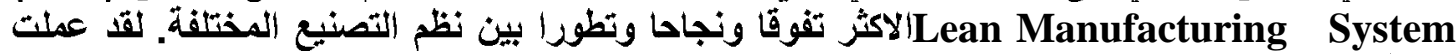

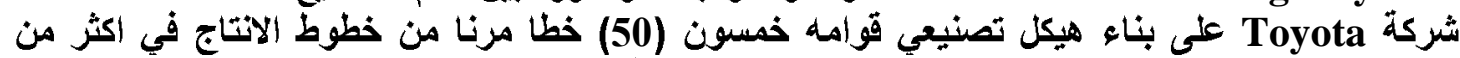

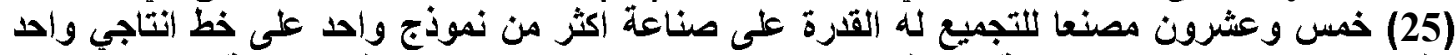

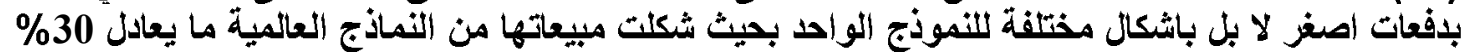

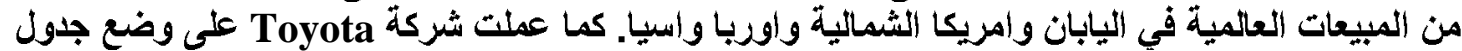

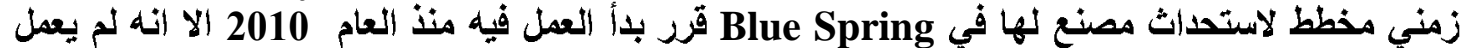

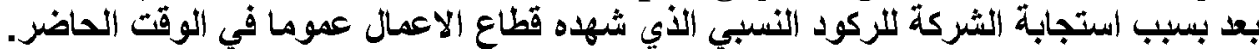

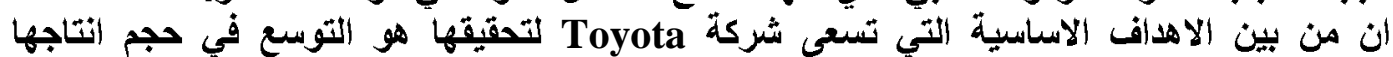

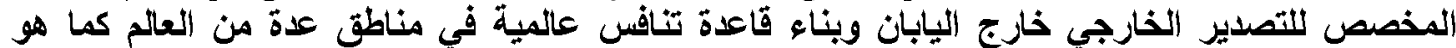

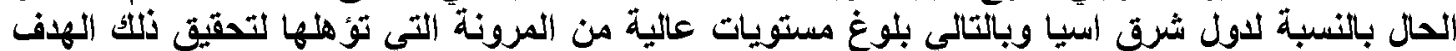

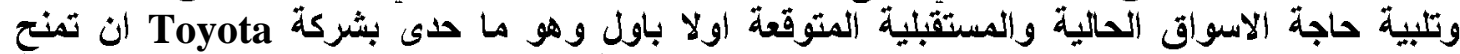

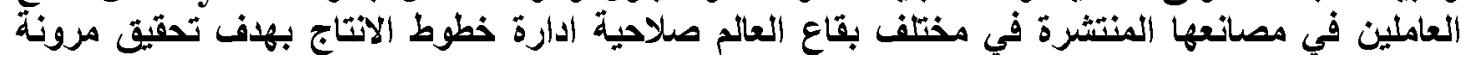

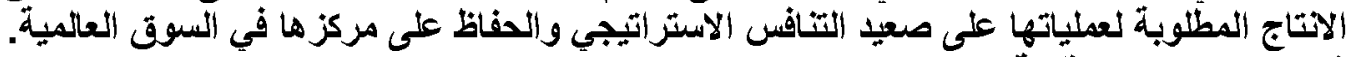

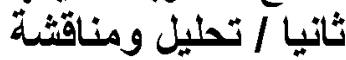

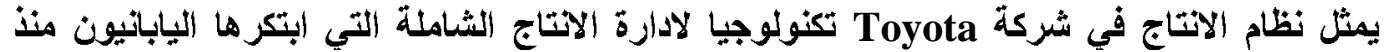

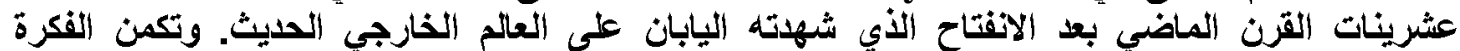

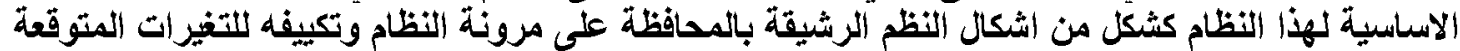

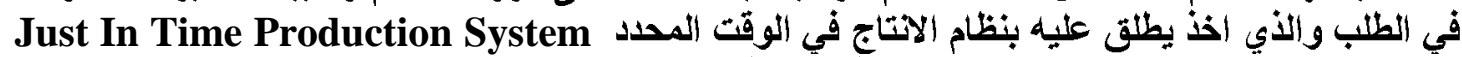

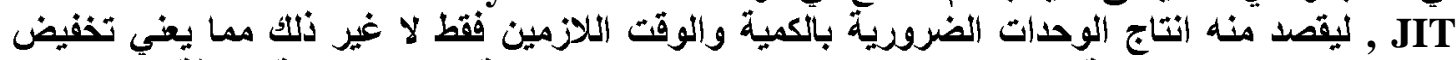

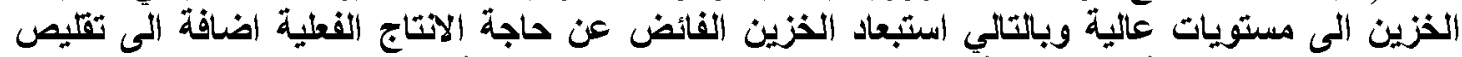

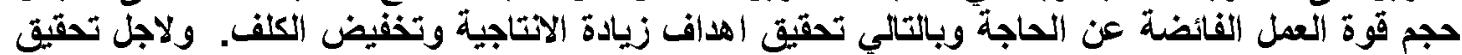

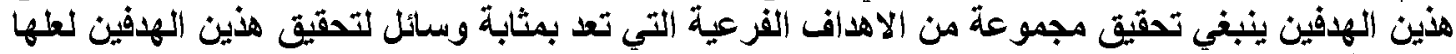

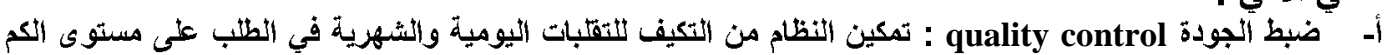
ت تجسد في الاتي : والنوع. ب- تاكيد الجودة quality assurance : التاكيد على تقديم كل عملية، تلك السلع غير المعيبة فقط و ترحيلها الى

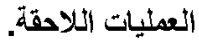

ج- احترام الجواتب الانسانية respect for humanity: احترام المورد البثري العامل وكرامته وانسائيته بما يصب في

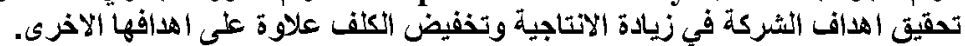

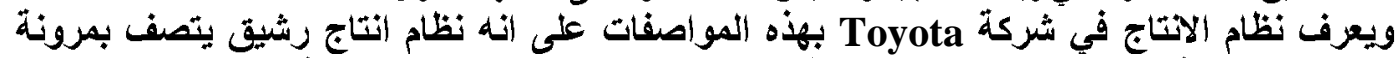

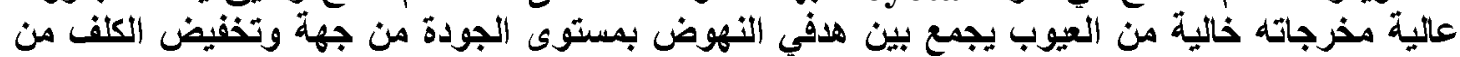

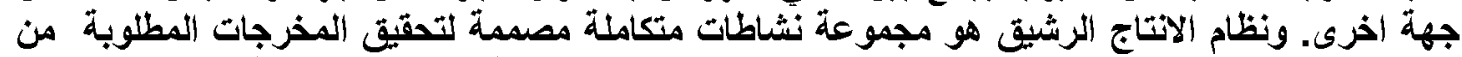

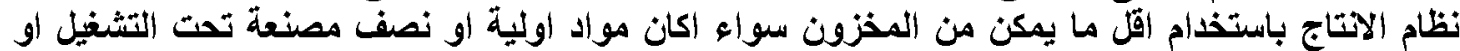

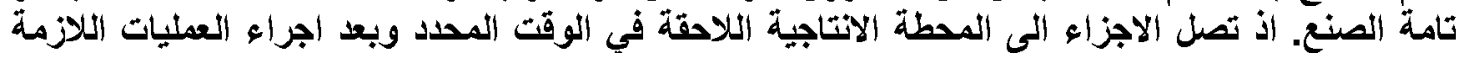




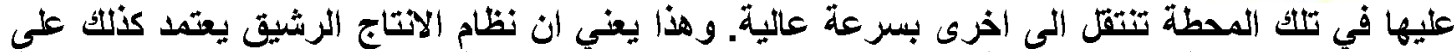

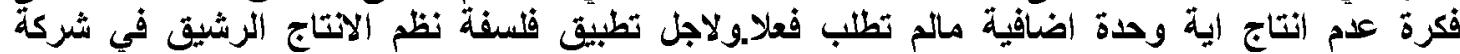
Toyota

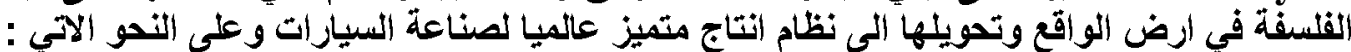

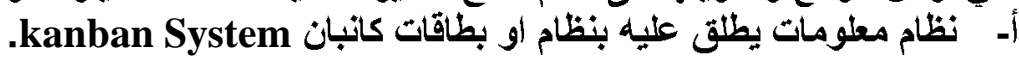

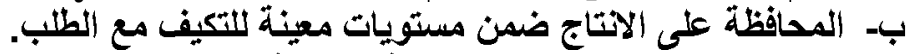

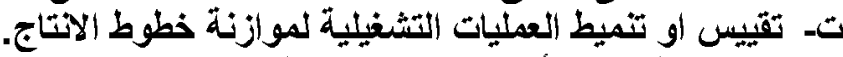

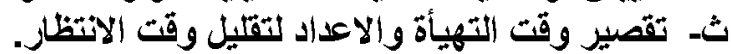

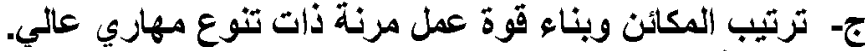

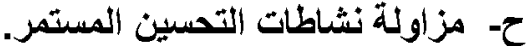

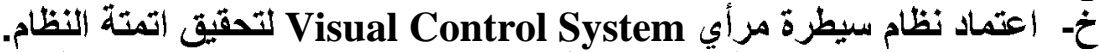
د- تبني نظام ادارة وظيفية النشر فلسفة ضبط الجودة في عموم ارجاء الثركة.

ويستتد نظام الانتاج المرن في شركة Toyota الى اربعة مبادئ اساسية يمكن توصيفها بالاتي:

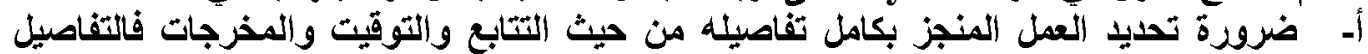
مهمة جدا لضمان قاعلية التحسين.

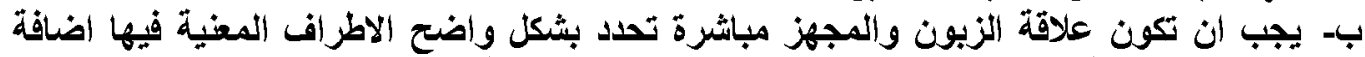

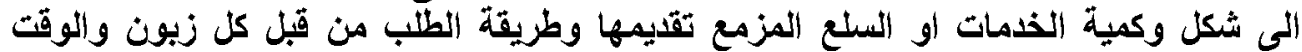
المتوقع لتفيذ او تلبية الطلبات.

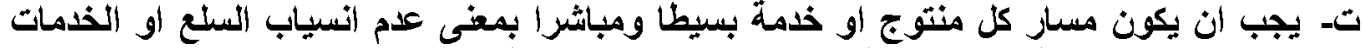

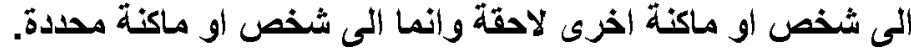

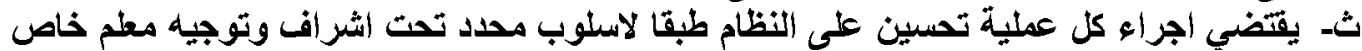
بألك عادة ما يكون المشرف المبلة المباشر. ثالثار تقويم نتائج التحليل

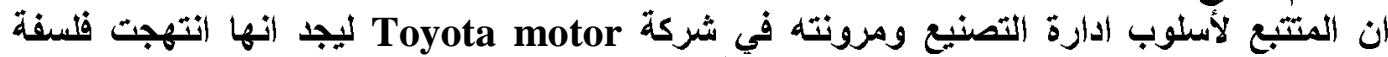

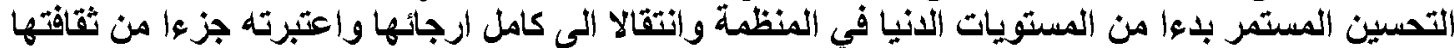

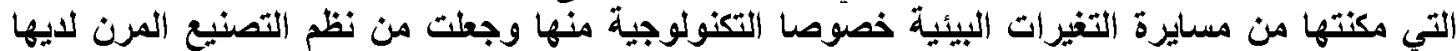
متجسدة بنظام الاتتاج الرشيق في اللوقت المحد

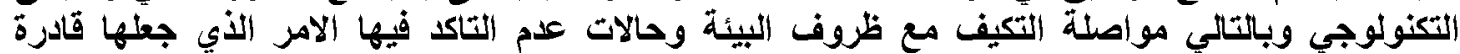

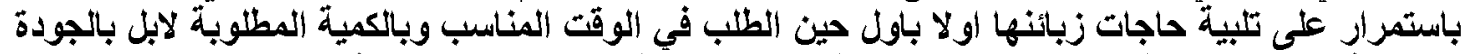

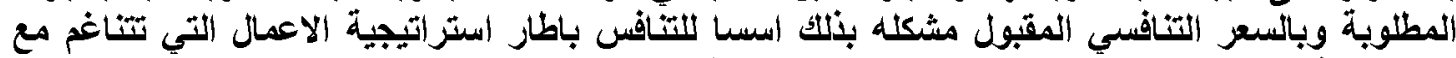

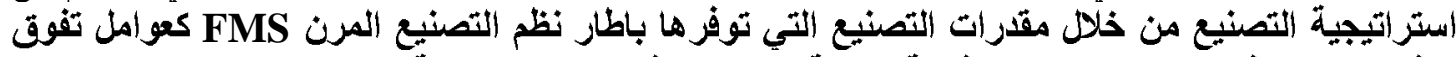

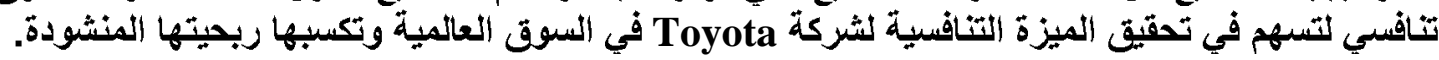


ان فلسفة التصنيع لدى شركة Toyota قوامها السعي الدؤوب نحو تفعيل عمليات التحسين المستمر في والتي

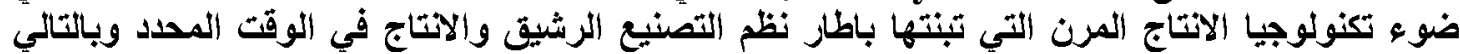

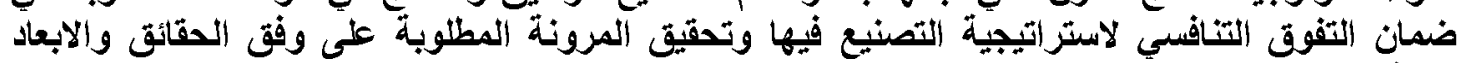
الاقية: مان

ان تبني شركة Toyota لنظام الانتاج المرن شكل انتقالية جذرية ذات طابع راديكالي للتحول من نظام i الاتتاج الواسع mass production الى نظام الانتاج الرشيق

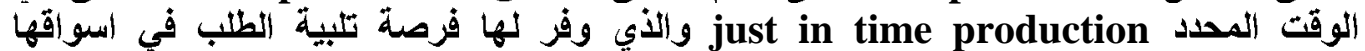

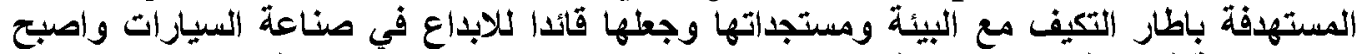

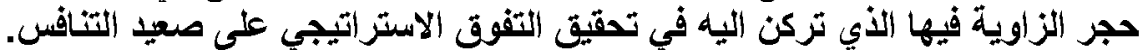

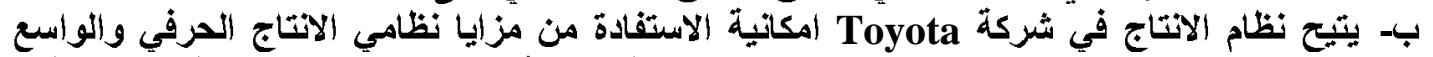

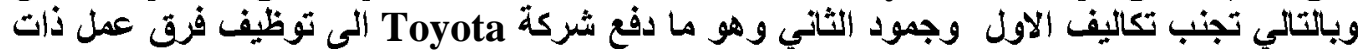

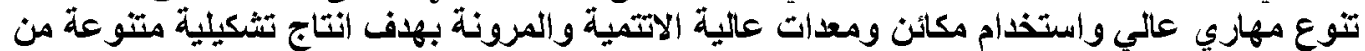

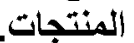

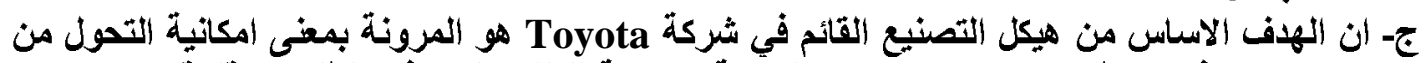

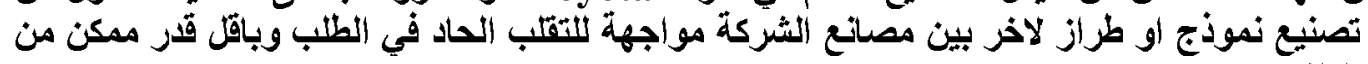
(لكلف

ذـ وبالتالي تاطرت استراتيجية الثركة في تصنيع السد يارات في الاسواق التي تأجّ في الطلب عليها و تصنطيع بيعها فيها. تصنا. هـ تمكنت شركة Toyota من بناء مناخ ثقافي مناسب يصلح لتطبيق نظم الانتاج الرشيق الأي يتطلب

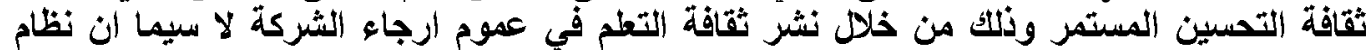

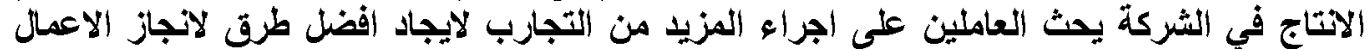
وتعمها ليصبحوا هم معلمون للآخرين. 


\section{خلاصة واستنتاجات}

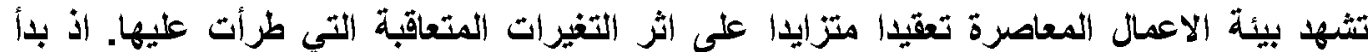

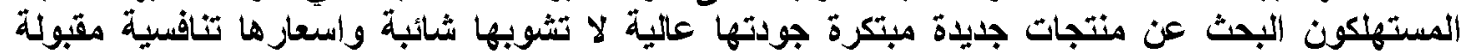

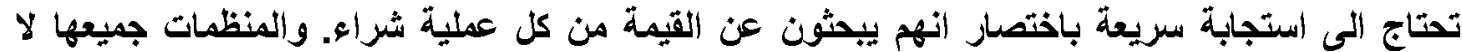

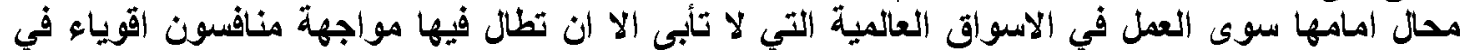

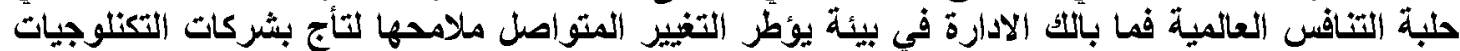

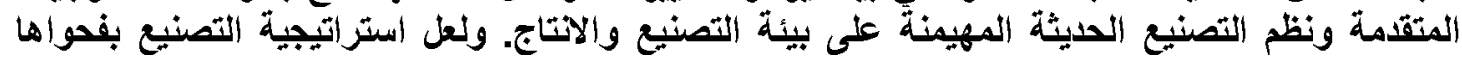

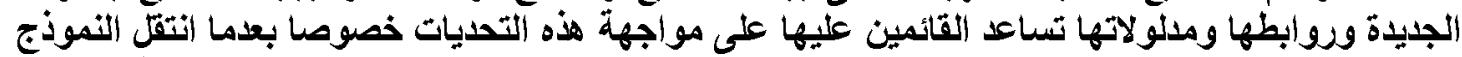

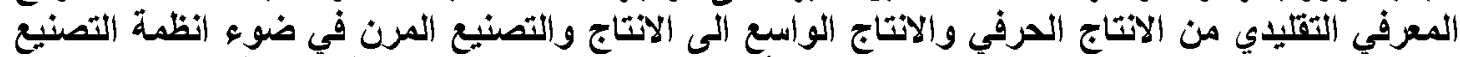

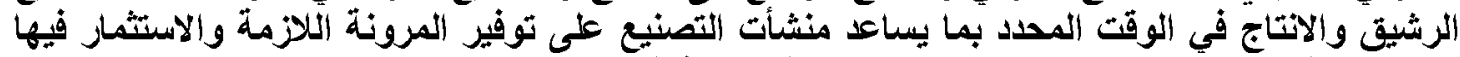

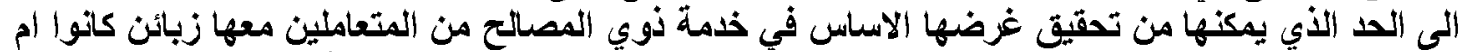

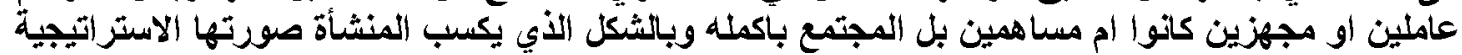

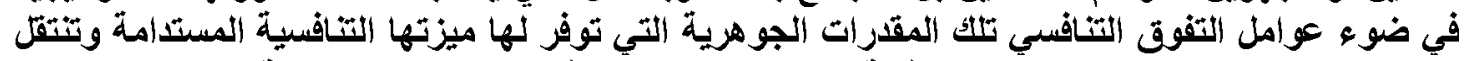

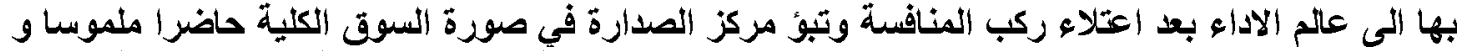

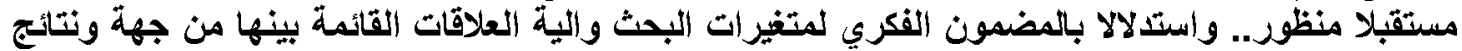

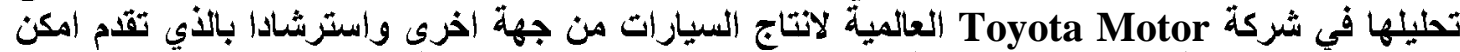

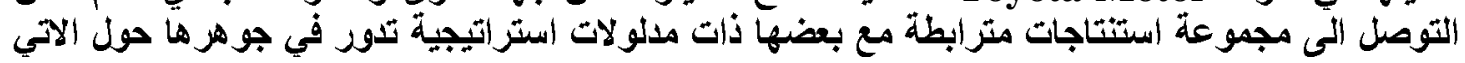

أ- ان الغزض التهائي لاستراتيجية التصنيع هو توليب قيمة وتقليمها الى الزبائن على شكل منتجات

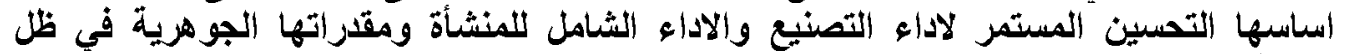

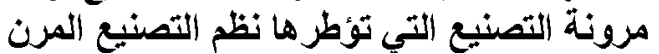

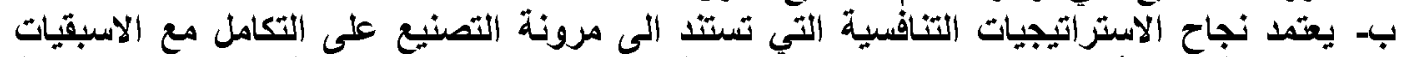

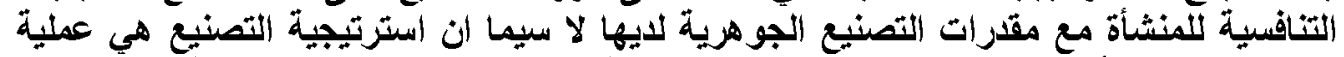

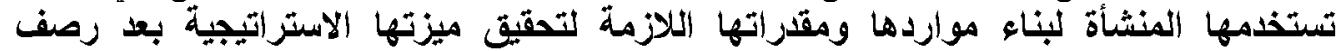

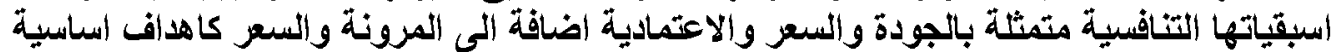
لادائ ادارة التصنيع والعمليات فيها.

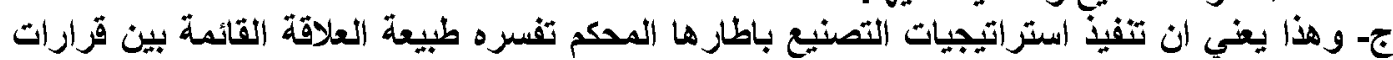

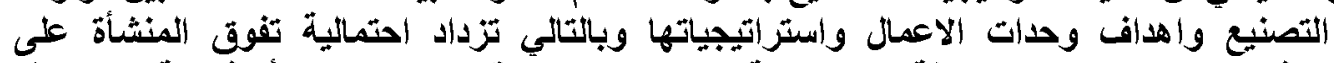

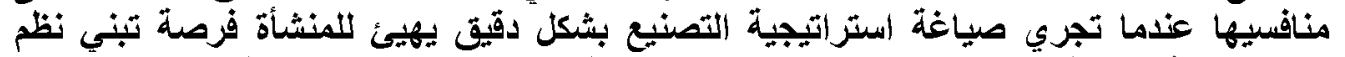

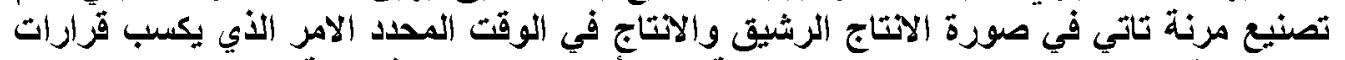

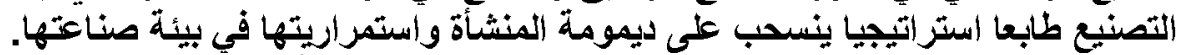

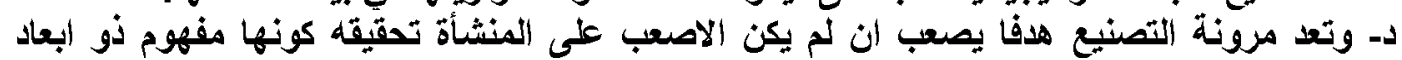

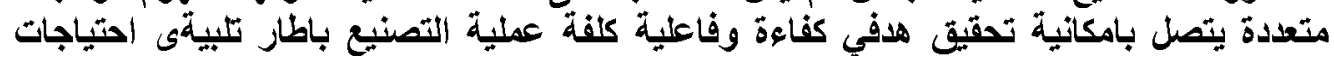

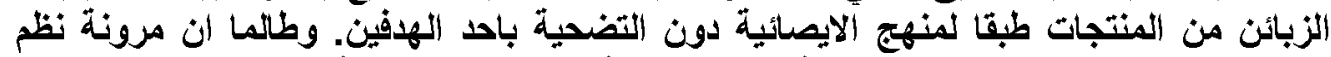

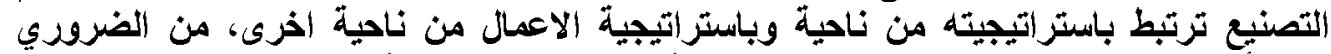

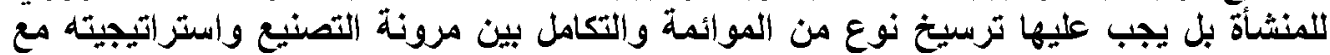

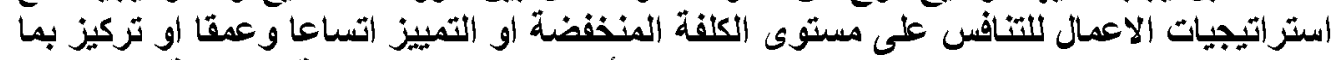

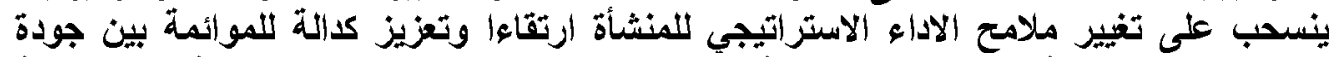

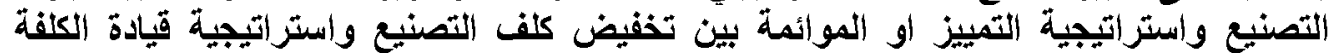


هـ اسفرت نتائج تحليل ومناقشة متغيرات البحث والعلاقات القائمة بينها على مستوى شركة Motor

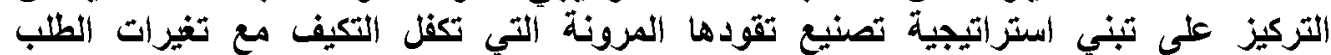

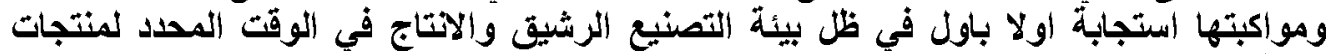

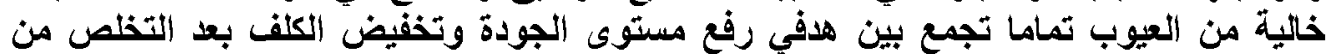

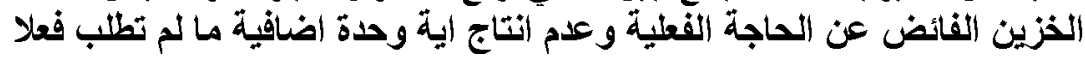

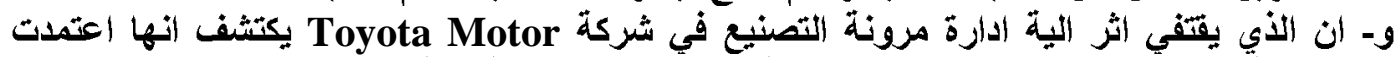

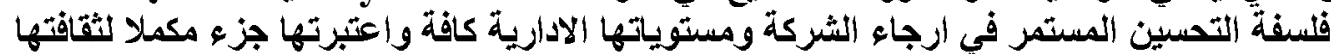

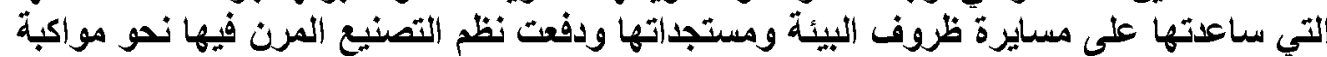

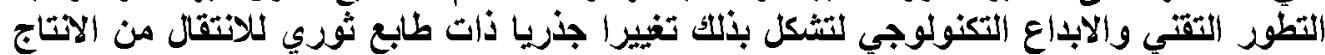

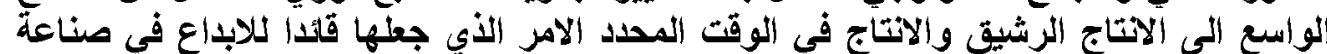

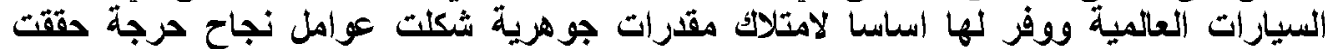

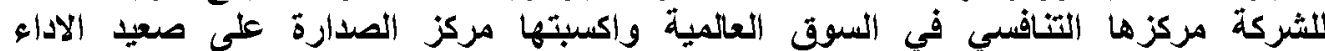
الاستراتيجى ويما يعزن من صحة فرضية البحث ومنطقية قبولها.

1. Aballah, Ayman Bahjat and Matsui, Yoshiki, the relationship between JIT production and manufacturing strategy and their impact on JIT performance,poms $18^{\text {th }}$. annual conference, Dallas, Texas, USA., 2007.

2. Bertr and, Jw.m, an over view of flexibility literature from the operations management perspective, (www. emeraldinsight. com /insight/html), 2002.

3. Das , Ajay, towards theory building in manufacturing flexibility, international journal of production research , vo.39, no.18,2001

4. Evans, r. James, production / operations management : quality, per formance and value, $5^{\text {th }}$.ed., west publishing company, 1997.

5. Ferdousi, farhana and ahmed, amir, a manufacturing strategy : an overview of related concepts, principles and techniques, asian journal of business management, vo.2,no.2, 2010.

6. Gupta, Yash p. and Somers, Toni m., business strategy, manufacturing flexibility, and organizational performance relationships: a path analysis approach , production and operations management society, 1996.

7. Heizer, Jay and Render, Barry, operations management, new jersey: pearson printice hall,2009.

8. Ichimaru, Yoichiro, Ikawa, Shoji , Ijichi , Takahiko , Ina , Koichi , Kobuki , Shinzo, and Nihashi Iwao, manufacturing stategy ,(hermes 0 ir. lib.hitv.ac.2009).

9. Jacobs , f. Robert, Chase, Richard b., and Aquilano, Nicholas j., operations and supply management, $12^{\text {th }}$.ed., USA: McGraw - Hill , 2009.

10. krajeuwski, lee j., Ritzman, larry, and Maihorta, Manoj k., operations management : processes and supply chains, $9^{\text {th }}$. ed., New Jersey : pearson printice hall,2010.

11. Nampiring, Norachai and Punglae, Sakol, the future of industrial automation flexible manufacturing systems (fms), (www.informa word.com)2002. 
12. Ramakrishnan, Rajesh and Benjaafar, Saifallah, Modeling, Measurement and Evaluation of Sequencing Flexibility in Manufacturing Systems, (www.informaword.com),1997.

13. Roberto, Guixiu Qiao and Mclean, Charles, Flexible Mannfacturing System for mass customization manufacturing , (www.mel.nist.gov.),2002.

14. Shivan and, h.k., Benal, M.and Koti , V., flexible manufacturing system new delhi: ,new age intenational (p) ltd.2006.

15. Slack, Nigle, Chambers, Stuart, and Johnston, Robert, operations management, $4^{\text {th }}$.ed., uk : person education limited , 2004.

16. Swamidass, M., Darlow,Neil, and Baines, Tim, Evolving forms of manufacturing strategy development :evidence and implications, (www.emerald - library.com /ft, 2001.

17. Tuluca, Sorin and Stalinski, Piotr, the manufacturing flexibility to switch products: valuation and optimal strategy, (repec.org./sce 2004), 2004.

18. Waldron, Darrvl G., manufacturing strategy : what does it take to be world class, ( www.sba.muohio.edu/abas), 1999. 